\title{
A multi-level hierarchic Markov process with Bayesian updating for herd optimization and simulation in dairy cattle
}

\author{
R. M. Demeter, ${ }^{\dagger} \dagger^{1}$ A. R. Kristensen,‡ J. Dijkstra,§ A. G. J. M. Oude Lansink, $†$ M. P. M. Meuwissen, $\dagger$ \\ and J. A. M. van Arendonk* \\ *Animal Breeding and Genomics Centre, Wageningen University, $6700 \mathrm{AH}$, Wageningen, the Netherlands \\ †Business Economics Group, Wageningen University, 6706 KN, Wageningen, the Netherlands \\ ‡Department of Large Animal Sciences, University of Copenhagen, DK 1870, Frederiksberg C., Denmark \\ §Animal Nutrition Group, Wageningen University, 6709 PG, Wageningen, the Netherlands
}

\begin{abstract}
Herd optimization models that determine economically optimal insemination and replacement decisions are valuable research tools to study various aspects of farming systems. The aim of this study was to develop a herd optimization and simulation model for dairy cattle. The model determines economically optimal insemination and replacement decisions for individual cows and simulates whole-herd results that follow from optimal decisions. The optimization problem was formulated as a multi-level hierarchic Markov process, and a state space model with Bayesian updating was applied to model variation in milk yield. Methodological developments were incorporated in 2 main aspects. First, we introduced an additional level to the model hierarchy to obtain a more tractable and efficient structure. Second, we included a recently developed cattle feed intake model. In addition to methodological developments, new parameters were used in the state space model and other biological functions. Results were generated for Dutch farming conditions, and outcomes were in line with actual herd performance in the Netherlands. Optimal culling decisions were sensitive to variation in milk yield but insensitive to energy requirements for maintenance and feed intake capacity. We anticipate that the model will be applied in research and extension.
\end{abstract}

Key words: economics, optimization, dairy cattle, Markov decision process

\section{INTRODUCTION}

The economic optimization of dairy herd performance is vital for dairy producers. In the past decades, models with optimization and simulation purposes have been used to support decision making in dairy herds re-

Received February 10, 2011.

Accepted July 15, 2011.

${ }^{1}$ Corresponding author: robert.demeter@wur.nl garding insemination and culling decisions. Optimizing insemination decisions is important because suboptimal calving intervals lead to financial losses (e.g., van Arendonk and Dijkhuizen, 1985; Dekkers, 1991). Optimizing cow replacement is important because the farmer's culling policy influences farm profitability as the direct costs related to replacement heifers represent a significant part of total costs (Lehenbauer and Oltjen, 1998; Fetrow et al., 2006). A large number of models have been developed to address the problem of economically optimal insemination and replacement strategies (see e.g., van Arendonk, 1984; Kristensen, 1994; Lehenbauer and Oltjen, 1998).

To model the optimization problem for inseminations and replacements, 2 main techniques have traditionally been applied: the marginal net revenue approach and the Markov decision process (MDP) approach. The main differences between the 2 approaches are that the MDP approach can account for seasonal variation, continuous genetic improvement, and variation within traits, whereas the marginal net revenue approach cannot (van Arendonk, 1984). The MDP approach, therefore, has been more frequently applied and was used in this study.

When using the MDP approach, optimal decisions depend on the criterion of optimality. Possible criteria of optimality include the maximization of total expected rewards, total expected discounted rewards, expected average rewards per unit of time, or expected average rewards per unit of expected physical input or output (Kristensen, 1994). The MDP can be optimized by value iteration, policy iteration, or linear programming (Kristensen, 1994). Each optimization method has been applied in dairy cattle. Value iteration has been used since the 1960s (e.g., Giaever, 1966; Stewart et al., 1977; van Arendonk, 1985b). Policy iteration has been applied since the 1980s (e.g., Kristensen, 1987, 1989; Houben et al., 1994; Mourits et al., 1999), after Kristensen $(1988,1991)$ introduced the notion of hierarchic Markov process (HMP). Linear programming has been the least used and, to our knowledge, only 2 
studies (Yates and Rehman, 1998; Cabrera, 2010) have used linear programming.

Two important methodological developments have been realized recently in the area of herd optimization. First, Kristensen and Jørgensen (2000) extended the concept of HMP by introducing the notion of multilevel hierarchic Markov process (MLHMP), which decreases the problem of the "curse of dimensionality," which refers to exponentially growing state space in real-world applications (Kristensen and Jørgensen, 2000). To date, few studies have applied the MLHMP technique in dairy cattle. Bar et al. (2008, 2009) estimated costs of generic clinical mastitis, whereas Cha et al. (2010) calculated the cost of different types of lameness. Nielsen et al. (2010) determined optimal culling decisions based on daily milk yield measurements. The above models were formulated as 3-level MLHMP and demonstrated that real-world applications with a large state space can be modeled efficiently.

Second, Nielsen et al. (2011) introduced a formal description of embedding a Bayesian updating technique into an MDP. Specifically, they provided a general framework for applying a state space model (SSM) in an MDP. State space models provide a statistical method for modeling variation in biological traits (between animals and over time). An SSM applies Bayesian updating to predict future development in the trait modeled, while taking all past information into account. The method contributes to the solution of the problem of "uniformity," which refers to the problem of defining and measuring highly variable biological traits (Ben-Ari et al., 1983; Kristensen, 1994). In dairy cattle, Nielsen et al. (2010) applied SSM to model daily milk yield in the context of automated milking systems. They also estimated herd-specific SSM variance parameters from daily milk yield records.

The objective of this study was to develop a dairy herd optimization and simulation model. The model determined economically optimal insemination and replacement decisions for individual cows (as described by a set of state variables) and simulated whole-herd results. The optimization problem was formulated as an MLHMP, and SSM was applied to model actual milk yield level. Optimal decisions were found by maximizing total expected discounted net revenues. Methodological contributions were presented in 2 main aspects. First, this study is the first to formulate a 4-level MLHMP for the dairy herd optimization problem to obtain more tractable and efficient model structure. Second, we incorporated a recently developed cattle feed intake model to obtain more precise predictions on feed intake and feed costs. In addition to methodological contributions, new biological parameters were used in the SSM and other biological functions. Results were presented for farming conditions in the Netherlands. In the future, the model will be used to assess herd-level implications of genetic selection strategies. This paper, therefore, reported whole-herd results to validate model behavior and evaluate methodological contributions and new biological parameters.

\section{MATERIALS AND METHODS}

The model consists of 2 parts: a bioeconomic module and a mathematical module. The bioeconomic module calculated technical and economic performance of individual cows during their productive life. The mathematical module optimized insemination and replacement decisions based on predictions from the bioeconomic module. Optimal decisions were found by maximizing total expected discounted net revenues. Optimal decisions were calculated for all individual cow states. A cow state was the combination of main properties characterizing a cow. A cow could be in a state described by one of 12 parities, 8 present-open periods, 8 previous-open periods, 18 lactation stages, 13 classes of estimated milk yield potential when entering the herd as heifer, 13 classes of updated milk yield potential when starting a new lactation, and 169 classes for actual milk yield level. The mathematical module, furthermore, simulated whole-herd results following optimal decisions for individual cows.

We considered only milk production and assumed that rearing young stock and producing feed crops were isolated from milk production. Replacement heifers and feedstuffs, therefore, were purchased from other separated business units or from the market. Farmer's labor was not included in calculation of costs, so net revenues represented financial compensation to the farmer for labor and management. Input values and model parameters were selected to simulate performance of HolsteinFriesian cows in the Netherlands (Table 1). The model worked with monthly $(30.5 \mathrm{~d})$ time intervals. The prices represented Dutch farming conditions during 2008 and 2009. Seasonality in performance and prices was not included.

The model included 2 key assumptions concerning herd constraints. First, fixed herd size was assumed; that is, a cow was immediately replaced after culling. The replacement problem, therefore, was treated as a single-component system, assuming an unlimited supply of heifers (Kristensen, 1992). This is not always valid in practice, because heifer supply is not exogenous to the farming process. Ben-Ari and Gal (1986) and Kristensen (1992) suggested treating the replacement problem as a multi-component system. The drawback 
Table 1. Summary of key price, biological, and management inputs used for the base scenario ${ }^{1}$

\begin{tabular}{|c|c|}
\hline Input & $\begin{array}{l}\text { Base } \\
\text { value }\end{array}$ \\
\hline \multicolumn{2}{|l|}{ Management input } \\
\hline Age at first calving (mo) & 24 \\
\hline Proportion of outdoor grazing on annual basis (\%) & 25 \\
\hline Proportion of concentrate in diet (\%) & 28 \\
\hline Length of keeping newborn calf (d) & 7 \\
\hline Minimum open period in lactation (mo) & 2 \\
\hline Maximum lactation length (mo) & 18 \\
\hline Annual discount rate (\%) & 5 \\
\hline \multicolumn{2}{|l|}{ Biological input } \\
\hline Mature mean 305-d milk yield ${ }^{2}(\mathrm{~kg})$ & 9,000 \\
\hline Mature mean 305-d fat content ${ }^{2}(\%)$ & 4.25 \\
\hline Mature mean 305-d protein content ${ }^{2}(\%)$ & 3.45 \\
\hline Variation coefficient of 305-d milk yield (\%) & 12 \\
\hline Heritability of milk yield & 0.40 \\
\hline Repeatability of consecutive $305-\mathrm{d}$ milk yields & 0.55 \\
\hline Correlation between true and estimated BV for milk yield & 0.60 \\
\hline Cow mature live weight $(\mathrm{kg})$ & 650 \\
\hline Calf birth weight $(\mathrm{kg})$ & 40 \\
\hline Calf survival rate in first week (\%) & 92 \\
\hline Length of estrus cycle (d) & 21 \\
\hline Heat detection rate (first estrus) & 0.30 \\
\hline Heat detection rate (later estruses) & 0.60 \\
\hline \multicolumn{2}{|l|}{ Price input $(€)$} \\
\hline Milk carrier ${ }^{3}(/ 100$ kg $)$ & -3.20 \\
\hline Milk fat ${ }^{3}(\mathrm{~kg})$ & 2.85 \\
\hline Milk protein $(\mathrm{kg})$ & 7.50 \\
\hline Roughage $^{3}(/ 100 \mathrm{~kg}$ of DM) & 10.12 \\
\hline Concentrate $^{3}(/ 100 \mathrm{~kg}$ of DM) & 16.25 \\
\hline Bull calf $^{3}(\mathrm{~kg})$ & 2.50 \\
\hline $\operatorname{Carcass}^{3}(\mathrm{~kg})$ & 1.75 \\
\hline Regular veterinary cost (per cow per $305-d)^{4}$ & 120 \\
\hline Cost of fixed production assets ${ }^{3}$ & 115 \\
\hline Monthly insemination cost (per cow $)^{4}$ & 25 \\
\hline Replacement heifer ${ }^{5}$ & 1,500 \\
\hline
\end{tabular}

of their approach was that finding an exact solution was computationally prohibitive. To date, no application has been reported, and finding an exact solution to the multi-component approach remains unsolved. Second, milk production quotas were not considered. Under production quotas, the herd constraint is a fixed amount of milk to produce. Maximization of expected average rewards per unit of expected output, therefore, is a more relevant criterion of optimality (Kristensen, 1991). Applying the latter criterion would solve the problem of selecting which cows to keep in the long run. The problem of determining how many cows to keep at a given time, however, would not be solved. The latter problem, in principle, could be solved by using the multiple-component approach with maximizing expected average rewards per unit of expected output (Kristensen, 1992). To date, however, such a method has not been developed.

\section{Bioeconomic Module}

The bioeconomic module was formulated by using the framework of van Arendonk (1985a). Relative to the original model of van Arendonk (1985a), the present model had 3 contributions: SSM was used to model milk yield and capture variation in milk yield potential among individual cows, novel insights on deriving feed intake capacity and actual feed intake were incorporated, and several new biological input values and parameters were included to reflect current population characteristics. We considered 3 revenues (milk, calves, and carcass) and 5 costs (feed, insemination, replacement heifer, loss due to involuntary culling, and sundries). Revenues and costs were calculated monthly, and their difference resulted in net revenues. The bioeconomic module, furthermore, was used to compute physical inputs and outputs, and transition probabilities for all 


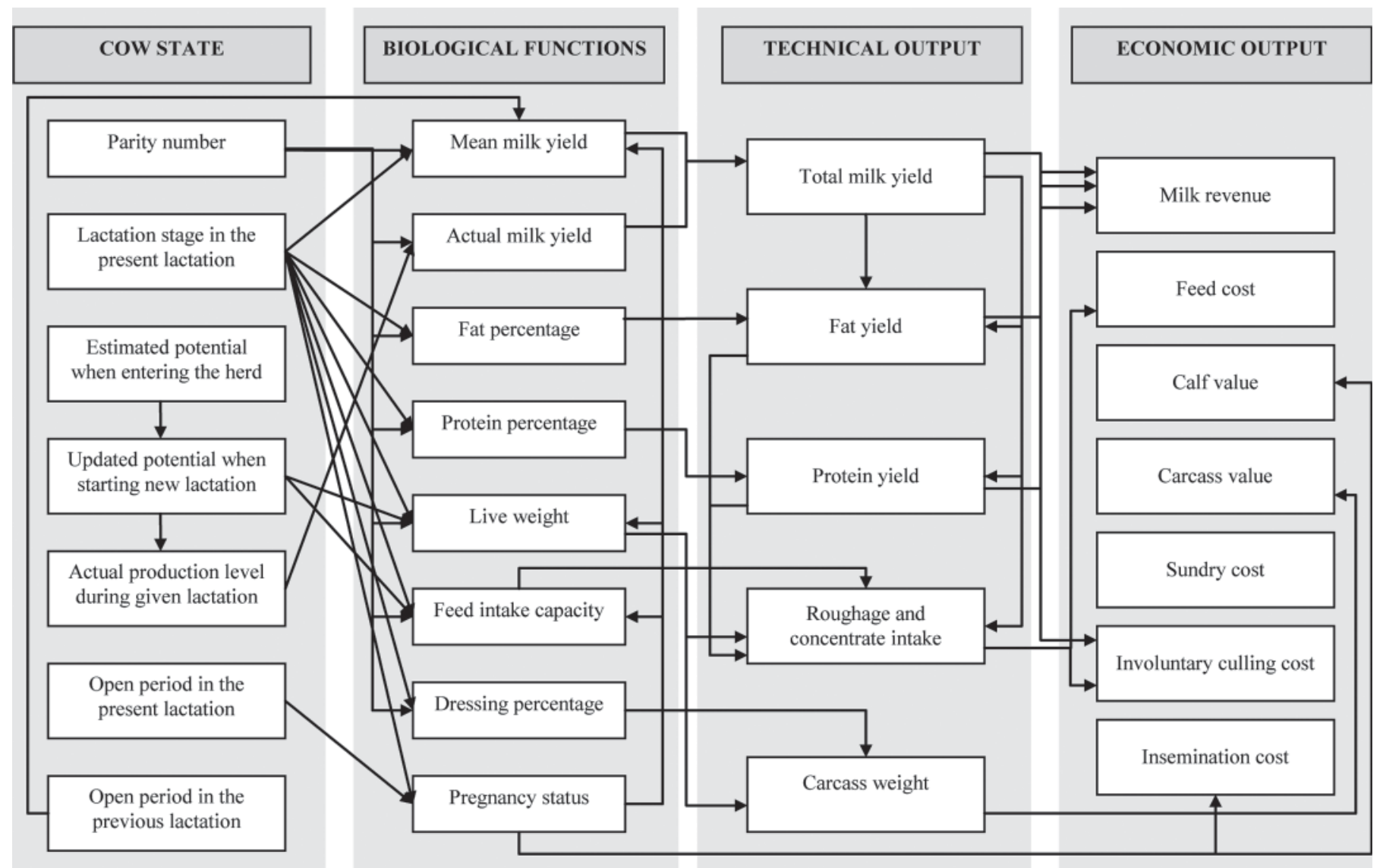

Figure 1. Schematic representation of the structure of the bioeconomic module (excluding transition probabilities and prices).

possible cow states. An overview of the bioeconomic module (excluding prices and transition probabilities) is shown in Figure 1.

Milk Yield. We assumed the following model for a cow's monthly total milk yield:

$$
M_{i, j}=\mu_{i, j}+\Sigma_{t} Y_{i, j, t}
$$

where $M_{i, j}$ was the total milk yield $(\mathrm{kg})$ in month $j$ in parity $i ; \mu_{i, j}$ was the mean milk yield $(\mathrm{kg})$ in month $j$ in parity $i$; and $Y_{i, j, t}$ was the daily deviation from the mean milk yield $(\mathrm{kg})$ on day $t$ in month $j$ in parity $i$. The term $Y_{i, j, t}$ captured the variation in milk yield among individual cows. For simplicity, we shall refer to the term $Y_{i, j, t}$ as actual milk yield, whereas the term $\mu_{i, j}$ shall be referred to as mean milk yield. In the following, we present the calculation of the actual yield, whereas deriving the mean yield is discussed in the appendix.

We assumed the following model for the actual milk yield (as deviation from the mean):

$$
Y_{i, j, t}=a g e_{i}^{\text {milk }} \times\left(B V+P E+X_{i, j, t}\right),
$$

where $Y_{i, j, t}$ was the actual daily milk yield $(\mathrm{kg})$ on day $t$ in month $j$ in parity $i$; age milk was the multiplicative effect of parity $i$ on milk yield; random variable $B V$ denoted the cow's permanent genetic capacity for milk yield (i.e., the breeding value for milk yield, $\mathrm{kg}$ ); random variable $P E$ denoted the effect of permanent environment on milk yield $(\mathrm{kg})$; and random variable $X_{i, j, t}$ denoted the within-lactation short-term fluctuation in milk yield $(\mathrm{kg})$ on day $t$ in month $j$ within parity $i$. Because both $B V$ and $P E$ are permanent properties of the cow over her entire lifetime, the model in equation [2a] was redefined by merging those effects as

$$
Y_{i, j, t}=a g e_{i}^{m i l k} \times\left(A+X_{i, j, t}\right),
$$

where random variable $A$ denoted the permanent production potential of the cow for milk yield $(\mathrm{kg})(A=$ $B V+P E)$, assuming that $A \sim \mathrm{N}\left(0, \sigma_{A}^{2}\right)$. Variable $X_{i, j, t}$ was assumed to follow a first-order autoregressive process with $X_{i, j, t} \sim \mathrm{N}\left(0, \sigma_{X}^{2}\right)$, where $\sigma_{X}^{2}$ was the variance of $X_{i, j, t}$, and autocorrelation $\rho(t)=\rho^{t}$, where $|\rho|<1$ (i.e., 
$\left.X_{i, j, t}=\rho \times X_{i, j, t-1}+\varepsilon_{i, j, t}\right)$. Variable $X_{i, j, t}$ can be interpreted as the cow's short-term deviation from her milk production potential due to temporary environmental effects, including feeding, management, and health problems.

We formulated an SSM to model actual milk yield over time, by adapting the framework of Nielsen et al. (2010). A dynamic linear model (DLM) was formulated with Kalman filtering (KF), as described by West and Harrison (1997). The term DLM refers to a specific SSM, where the model contains normally distributed variables with linear relationship. The DLM for actual milk yield was described by the following observation and system equations:

$$
\begin{gathered}
Y_{i, j, t}=F_{i} \otimes\left[\begin{array}{c}
A \\
X_{i, j, t}
\end{array}\right], \text { where } F_{i}=\operatorname{age} e_{i}^{\text {milk }}, \quad[3 \mathrm{a}] \\
{\left[\begin{array}{c}
A \\
X_{i, j, t}
\end{array}\right]=\mathbf{G} \times\left[\begin{array}{c}
A \\
X_{i, j, t-1}
\end{array}\right]+\mathbf{w}_{i, j, t}, \mathbf{G}=\left[\begin{array}{ll}
1 & 0 \\
0 & \rho
\end{array}\right], \text { and } \mathbf{w}_{i, j, t}=\left[\begin{array}{c}
0 \\
\varepsilon_{i, j, t}
\end{array}\right],}
\end{gathered}
$$

where $\mathbf{w}_{i, j, t} \sim N(0, \mathbf{W})$, with

$$
\mathbf{W}=\left[\begin{array}{cc}
0 & 0 \\
0 & \left(1-\rho^{2}\right) \times \sigma_{X}^{2}
\end{array}\right] .
$$

First, the observation equation (equation [3a]) specified the relationship between the observed variable $\left(Y_{i, j, t}\right)$ and the latent variables $\left(A, X_{i, j, t}\right)$. Second, the system equation (equation [3b]) specified the relationship between the latent variables $\left(A, X_{i, j, t}\right)$ from time $t-1$ to time $t$. Furthermore, $\mathbf{W}$ denoted the covariance matrix of random variable $\mathbf{w}_{i, j, t}$ in parity $i$.

We assumed that the conditional prior distribution of the latent variables given all available information (denoted by $\mathbf{D}$ ) available up to the beginning of any parity $i$ was $\left(A, X_{i, 0,0}\right)^{\prime} \mid \mathbf{D}_{i, 0,0} \sim \mathrm{N}\left(\mathbf{m}_{i, 0,0}, \mathbf{C}_{i, 0,0}\right)$, where mean and covariance matrices were specified as

$$
\mathbf{m}_{i, 0,0}=\left[\begin{array}{c}
\hat{A}_{i, 0,0} \\
0
\end{array}\right] \text { and } \mathbf{C}_{i, 0,0}=\left[\begin{array}{cc}
\sigma_{e_{i, 0,0}}^{2} & 0 \\
0 & \sigma_{X}^{2}
\end{array}\right],
$$

where $\hat{A}_{i, 0,0}$ denoted the prior expectation of the cow's permanent production potential before she would start producing in given parity $i$, and $\sigma_{e_{i, 0.0}}^{2}$ denoted the variation around $\hat{A}_{i, 0,0}$.

For $i=1, \hat{A}_{i, 0,0}$ in equation [4] can be interpreted as the prior estimate of the cow's permanent potential for milk yield. We allowed $\hat{A}_{i, 0,0}$ to have different values; that is, replacement heifers differed in permanent potential for milk yield when entering the herd. This was different from the DLM of Nielsen et al. (2010), because they assumed cows to be average heifers when entering the herd; that is, $\hat{A}_{i, 0,0}=0$. For $i>1, \hat{A}_{i, 0,0}$ in equation [4] can be interpreted as the updated estimate of the cow's permanent potential for milk yield. For $i>1$, $\hat{A}_{i, 0,0}$ was always set equal to $\hat{A}_{i-1, J, 1}$, where $J$ denotes the last month within parity $i-1$ when the cow was still producing. That is, the expectation for the cow's permanent milk yield potential at the beginning of parity $i$ was always set equal to its estimated value on the first day of the last producing month in parity $i-1$. For example, if $\hat{A}_{i, 0,0}$ equaled 5 in any parity $i$, it meant that the cow was estimated to have $5 \mathrm{~kg}$ of additional daily yield relative to the mean in parity $i-1$, and was expected to have $5 \mathrm{~kg}$ of additional daily yield in the following parities.

The variance $\sigma_{e_{i, 0,0}}^{2}$ in equation [4] can be interpreted as estimation uncertainty for the cow's permanent production potential. This estimation uncertainty was updated and reduced through the learning process from having monthly observations on the cow's actual milk yield. Each time a new observation was made, the estimate of the cow's permanent production potential $(\hat{A})$ became more accurate. For $i=1, \sigma_{e_{i, 0,0}}^{2}$ can be interpreted as the prior uncertainty that was specified to initialize the DLM. In fact, the value of $\sigma_{e_{1,0,0}}^{2}$ was the conditional variance of the cow's latent $A$ value given her EBV for milk yield. For $i>1, \sigma_{e_{i, 0,0}}^{2}$ can be interpreted as the updated uncertainty. For $i>1$, the value of $\sigma_{e_{i, 0,0}}^{2}$ was always set equal to $\sigma_{e_{i-1, J, 1}}^{2}$, where $J$ denotes the last month within parity $i-1$ when the cow was still producing. That is, estimation uncertainty at the beginning of parity $i$ was always set equal to its value on the first day of the last producing month in parity $i$ -1 .

We used KF to make predictions for actual milk yield and update posterior distributions of the latent variables. Predictions were made daily, whereas updates were made monthly. First, regarding daily predictions by $\mathrm{KF}$, let $\mathbf{D}_{i, j, 1}=\left(Y_{i, 1,1}, Y_{i, 2,1}, Y_{i, 3,1}, \ldots, Y_{i, j, 1}, \mathbf{m}_{i, 0,0}, \mathbf{C}_{i, 0,0}\right)$ denote a cow's actual daily milk yields on the first day in each month up to month $j$ in parity $i$, including prior information about the latent variables. Then, by letting $\mathbf{m}_{i, j, 1}$ denote the conditional mean of the latent variables on the first day in month $j$ in parity $i$, it follows that

$$
\mathbf{m}_{i, j, 1}=\left[\begin{array}{c}
\hat{A}_{i, j, 1} \\
\hat{X}_{i, j, 1}
\end{array}\right]=\mathbb{E}\left[\left[\begin{array}{c}
A \\
X_{i, j, t}
\end{array}\right] \mid \mathbf{D}_{i, j, 1}\right] .
$$


Given the posterior distribution of the latent variables on the first day in month $j$ in parity $i$; that is, $\left(A, X_{i, j, 1}\right)^{\prime} \mid \mathbf{D}_{i, j, 1} \sim \mathrm{N}\left(\mathbf{m}_{i, j, 1}, \mathbf{C}_{i, j, 1}\right)$, KF was used to predict actual daily milk yield for each day $t$ in month $j$ in parity $i$ (Theorem 4.1 in West and Harrison, 1997) as

$$
\mathbb{E}\left(Y_{i, j, t} \mid \mathbf{D}_{i, j, 1}\right)=a g e_{i}^{\text {milk }} \times\left(\hat{A}_{i, j, 1}+\rho^{t-1} \times \hat{X}_{i, j, 1}\right) .
$$

The expected total monthly milk yield for any month $j$ in parity $i$ was then obtained by summing expected actual daily milk yields and adding monthly mean milk yield as

$$
\mathbb{E}\left(M_{i, j} \mid \mathbf{D}_{i, j, 1}\right)=\mu_{i, j}+\sum_{t} \mathbb{E}\left(Y_{i, j, t} \mid \mathbf{D}_{i, j, 1}\right) .
$$

Second, regarding monthly updates by KF, given all information available up to the first day in month $j$ in parity $i$, the conditional distribution of $\left(\mathbf{m}_{i, j+1,1} \mid \mathbf{m}_{i, j, 1}\right)$ was the multivariate normal distribution (adapted from Nielsen et al., 2010):

$$
\begin{aligned}
& {\left[\left(\hat{A}_{i, j+1,1}, \hat{X}_{i, j+1,1}\right) \mid\left(\hat{A}_{i, j, 1}, \hat{X}_{i, j, 1}\right)\right]} \\
& \sim \mathrm{N}\left[\left(\hat{A}_{i, j, 1}, \rho^{30.5} \hat{X}_{i, j, 1}\right),\left(Q_{i, j+1,1} \mathbf{B}_{i, j+1,1} \mathbf{B}_{i, j+1,1}^{\prime}\right)\right],
\end{aligned}
$$

with $\quad \mathbf{B}_{i, j+1,1}=\mathbf{R}_{i, j+1,1} F_{i} Q_{i, j+1,1}^{-1}, \quad \mathbf{R}_{i, j+1,1}=\mathbf{G C}_{i, j, 1} \mathbf{G}^{\prime}+\mathbf{W}$, and $Q_{i, j+1,1}=F_{i} \mathbf{R}_{i, j+1,1} F_{i}$. The scalar $F_{i}$ and the matrices $\mathbf{G}$ and $\mathbf{W}$ were defined in equations [3a], [3b], and [3c], respectively. By having monthly updates, we assumed that a single record on actual milk yield was available monthly. We chose this approach to mimic the test-day milk recording system used in the Netherlands. Because it was reasonable to assume that actual milk yield was known with certainty once a month, no measurement error was included in the model for actual milk yield in equation $[2 \mathrm{~b}]$. We assumed that monthly updates occurred on the first day of the month. Thus, $\hat{A}_{i, 0,0}$ and $\sigma_{e_{i, 0,0}}^{2}$ were set equal to $\hat{A}_{i-1, J, 1}$ and $\sigma_{e_{i-1, J, 1}}^{2}$ for $i>1$. Because of monthly updating, monthly transitions between actual milk yield classes were allowed. Monthly updating was different from Nielsen et al. (2010), who used KF to update daily.

The variance structure of the SSM can be described by the parameters $\sigma_{A}^{2}, \sigma_{X}^{2}, \sigma_{e_{1,0,0}}^{2}$, and $\rho$. In Nielsen et al. (2010), these parameters (together with mean milk yield) were estimated by analyzing herd data from daily milk recordings. In this study, however, we used a more general approach. We derived parameters that were not dependent on a specific herd or method of milk collection. Variance parameters were based on available literature information (details described in the appendix). The advantage of using literature-based parameters is that this approach does not require extensive data analyses, and adjustments to other production conditions are less complicated. Note, however, when the intention is to use the model on a farm, using herd-specific parameters is advantageous. The purpose of the model, therefore, determines which parameters should be used. Because this model was built primarily for research purposes, we used variance parameters that were based on literature information.

Milk Revenues. Monthly milk revenues were calculated from monthly yields of milk, fat, and protein. Calculations for fat and protein yields are discussed in the appendix. According to the current payment scheme in the Netherlands, the amount of milk was penalized, whereas the amount of fat and protein were rewarded. The base milk payment prices are in Table 1.

Feed Intake. The feed intake was derived from total energy requirement, which equaled the energy required for maintenance, production, weight gain, and pregnancy, minus the energy available from fat mobilization. Energy requirement depended on age, lactation stage, and pregnancy stage. Energy from the feed ration had to meet total energy requirement. We assumed that the feed ration contained sufficient amount of protein and other nutrients. Feed intake, therefore, was determined by only total energy requirement. Energy was expressed in VEM (Dutch feed units of net energy), where 1,000 VEM was equivalent to $6.9 \mathrm{MJ}$ of net energy (NE). Feed intake, NE, satiety values, and prices were expressed on a DM basis.

First, total monthly NE requirement was computed, which included NE requirement for maintenance, milk production, live weight change (positive or negative), and pregnancy. Energy requirement of maintenance and milk production was calculated from (CVB, 2007)

$$
\begin{aligned}
\text { ader }_{i, j}= & \left(42.4 \times \text { alw }_{i, j}^{0.75} \times 1.05+442 \times a d f p c m_{i, j}\right) \\
& \times\left[1+\left(\text { adfpcm }_{i, j}-15\right) \times 0.00165\right],
\end{aligned}
$$

where $a d e r_{i, j}$ was the average daily NE required (VEM per day) for maintenance and milk production in month $j$ in parity $i$; $a l w_{i, j}$ was the average live weight $(\mathrm{kg})$ in month $j$ in parity $i$; and $a d f p c m_{i, j}$ was the average daily fat- and protein-corrected milk (FPCM; $\mathrm{kg} / \mathrm{d}$ ) in month $j$ in parity $i$. The calculations of $a l w_{i, j}$ and adfpcm $_{i, j}$ are given in the appendix. We assumed that energy requirement for maintenance was influenced by time spent on outdoor grazing. Cows that are managed 
in a full time (24-h daily) outdoor grazing farming system have 20\% higher NE requirements for maintenance than cows housed in freestall barns (CVB, 2007). Because cows in the Netherlands are usually kept outside for $6 \mathrm{mo}$ of the year for $12 \mathrm{~h} / \mathrm{d}$, the basic energy requirement for maintenance in equation [9] was increased by $5 \%$.

Energy requirement of weight gain was calculated based on the ADG in the given month. The ADG, which accounted for age-related growth and reserve tissue deposition, was calculated using the live weight function described in the appendix, excluding the effect of pregnancy. In the lactating months, energy requirement of weight gain was 3,000 VEM per $\mathrm{kg}$ of live weight (CVB, 2007). In the dry months, $10 \%$ higher energy requirement was used because weight gain is less efficient in this period (van Arendonk, 1985a). In the months when the cow mobilized reserve tissue, total NE requirement was decreased by energy from fat mobilization. We assumed that reserve tissue was utilized with $80 \%$ efficiency (CVB, 2007), so NE from $1 \mathrm{~kg}$ of mobilized reserve tissue equaled 2,400 VEM.

Energy requirements of pregnancy were set to 450 , 850, 1,500, and 2,700 VEM per day within mo 6, 7, 8 , and 9 of pregnancy, respectively. We assumed, furthermore, that the energy requirement of pregnancy in earlier months was negligible (CVB, 2007).

Second, monthly feed intake capacity was computed. The cow's feed intake capacity depended on her parity, lactation stage, and pregnancy stage. Feed intake capacity was computed using a recently developed cattle feed intake model in the Netherlands (CVB, 2007). The daily feed intake capacity was expressed in satiety values $(\mathbf{S V})$ and was calculated as

$$
d f i c=\left(\begin{array}{c}
\left\{\alpha_{0}+\alpha_{1} \times\left[1-\exp \left(-\rho_{\alpha} \times \alpha\right)\right]\right\} \times \\
\left\{\beta \times\left[1-\exp \left(-\rho_{\beta} \times d\right)\right]\right\}
\end{array}\right) \times[1-\delta \times(g / 220)] \text {, }
$$

where $d f i c$ was the daily feed intake capacity expressed in SV; $\alpha$ was an input value expressing the age of the cow ( $\alpha=$ parity $-1+$ number of days in lactation/365); $d$ was an input value expressing the number of days in lactation; $g$ was an input value expressing the number of days pregnant; $\alpha_{0}$ was a parameter describing the initial feed intake capacity in the first parity $(\mathrm{SV} / \mathrm{d})$; $\alpha_{1}$ was a parameter describing the asymptotic level of maximum increase of daily feed intake capacity $(\mathrm{SV} / \mathrm{d})$; $\rho_{\alpha}$ was a parameter for the rate of increase in feed intake capacity (per day); $\beta$ was a parameter describing the maximum level of adjustment for stage of lactation relative to the basic curve; $\rho_{\beta}$ was a parameter for the rate of increase in feed intake capacity at the beginning of the lactation (per day); and $\delta$ was a pregnancy parameter. The values of $\alpha_{0}, \alpha_{1}, \rho_{\alpha}, \beta, \rho_{\beta}$, and $\delta$ were set to $8.743,3.563,1.140,0.3156,0.05889$, and 0.05529 , respectively (CVB, 2007). Because cows with higher milk yield potential generally have higher feed intake capacity, we adjusted $d f i c$ in such way that every $1 \%$ increase in milk yield potential resulted in $0.32 \%$ increase in dfic. Daily feed intake capacities were summed monthly to derive the cow's monthly feed intake capacity.

Third, the monthly total NE requirement and the monthly feed intake capacity were combined to obtain monthly feed rations. Average ration was assumed to contain $72 \%$ roughage and $28 \%$ concentrate (Van Bruggen, 2008). Roughage composition was assumed to be $26.4 \%$ fresh grass, $40.3 \%$ grass silage, and $33.3 \%$ maize silage (Van Bruggen, 2008). The NE content and SV of the roughage components were assumed to be: 955 $\mathrm{VEM} / \mathrm{kg}$ of DM and $0.91 \mathrm{SV} / \mathrm{kg}$ of DM for fresh grass; $889 \mathrm{VEM} / \mathrm{kg}$ of $\mathrm{DM}$ and $1.03 \mathrm{SV} / \mathrm{kg}$ of $\mathrm{DM}$ for grass silage; and $958 \mathrm{VEM} / \mathrm{kg}$ of DM and $0.81 \mathrm{SV} / \mathrm{kg}$ of DM for maize silage. The weighted NE content and SV of roughage were $929 \mathrm{VEM} / \mathrm{kg}$ of $\mathrm{DM}$ and $0.93 \mathrm{SV} / \mathrm{kg}$ of DM. Concentrate was assumed to be standard concentrate with an NE content of 1,044 VEM/ $\mathrm{kg}$ of DM and $\mathrm{SV}$ of $0.32 \mathrm{SV} / \mathrm{kg}$ of DM. The NE contents and SV were obtained from near-infrared reflectance spectroscopy carried out by Blgg (Oosterbeek, the Netherlands). Monthly ration was computed by maximizing roughage intake. Restrictions were imposed to ensure that the NE content of the ration met the monthly total $\mathrm{NE}$ requirement; the actual feed intake $(\mathrm{SV} / \mathrm{mo})$ was not higher than the monthly feed intake capacity; and a minimum of $2 \mathrm{~kg}$ of concentrate was given to the cows daily.

Feed Costs. Roughage price per kilogram of DM was $€ 0.072$ for fresh grass, €0.104 for grass silage, and $€ 0.122$ for maize silage (KWIN, 2009). The prices of roughages were weighted with their proportion in total roughage. Weighted roughage and concentrate prices are in Table 1.

Calf Revenues. We assumed that newborn calves were sold 1 wk after birth. Calf value was based on birth weight, survival rate, and price. Average birth weight was $40 \mathrm{~kg}$ in each parity (KWIN, 2009). Survival rate, including the first week after birth, was $92 \%$ in each parity (KWIN, 2009). The price for bull calf was $€ 2.5$ per $\mathrm{kg}$ (Table 1 ), and the value of heifer calf was $€ 40$ lower than that of a bull calf (KWIN, 2009). We assumed equal probabilities for having a bull or heifer calf. To account for costs during the first week after birth, €4.5 was subtracted from calf value. This cost equaled the price of $3 \mathrm{~kg}$ of skim milk powder that is normally given to newborn calves in the Netherlands during the first week after birth (KWIN, 2009). 
Weighting the values of bull and heifer calves with the chances of having them, the average calf value equaled $€ 69$, which was already corrected for costs during the first week after birth. Calf revenues were assigned to the first month of lactation.

Carcass Revenues. The carcass value of a cow was determined by her live weight, her dressing percentage (proportion of carcass weight in live weight), and the carcass price. Live weight was calculated using the function described in the appendix, excluding the effect of pregnancy. Dressing percentage depended on parity and lactation stage. Specifically, dressing percentage was computed from the average dressing percentage for a given parity and the additive adjustment factor for the month within lactation. The input values were taken from van Arendonk (1985a). The carcass price, which was already adjusted for costs associated with the sale of the animal, is in Table 1 . The calculation of carcass revenue described thus far referred to cows that were culled because of low production or poor fertility (i.e., voluntary culling). The calculation of carcass revenue from cows that were culled because of other reasons (i.e., involuntary culling) is discussed in the subsection on involuntary culling.

Sundry Costs. This category included 3 cost items. First, we imposed an interest rate ( $5 \%$ annually) on the cow's carcass value at the beginning of each month. Should the farmer decide to keep the cow for another month, the interest that could have been realized in that month on the carcass revenue represents an opportunity cost. Second, sundries included veterinary costs. In the Netherlands, the average veterinary cost for a mature cow is about €135 per year (KWIN, 2009), which is an average for healthy and diseased cows. The veterinary costs of healthy cows, therefore, are somewhat lower. Within lactation, veterinary costs were $€ 40$ in mo $1 ; € 10$ in mo 2, 3, and $4 ; € 15$ in the first dry month; and $€ 5$ in all other months (H. Hogeveen, Utrecht University, the Netherlands; personal commu- nication). Veterinary costs were the same in each parity. Third, we included the cost of fixed production assets (Table 1), which accounted for the aggregate expenses of stable, milking parlor, milk tank, manure and feed storage, grazing land, machinery, water, and electricity.

Reproduction and Related Costs. The monthly marginal probabilities of conception following insemination were calculated by using the approach of Mourits et al. (1999). The monthly marginal conception probabilities were calculated from heat detection rates (Table 1) and conception rates. The conception rates were corrected for parity and lactation stage. Average conception rates for each parity were taken from Jalvingh et al. (1993). Parity-specific average conception rates were then corrected for lactation stage by multiplicative adjustment factors from Inchaisri et al. (2010). Heat detection rates and conception rates were independent of milk yield potential and length of previous calving interval. Heat detection rates, furthermore, were independent of parity. The monthly marginal probabilities of conception are presented in Table 2 . The prices of first and later inseminations are around $€ 27$ and €15, respectively, in the Netherlands (H. Hogeveen, Utrecht University, the Netherlands; personal communication). For simplicity, however, we assigned a fixed cost of $€ 25$ to the month of insemination, and this cost also accounted for re-inseminations during the given month.

Involuntary Culling and Related Costs. Replacements for reasons other than low production or failure to conceive were referred to as involuntary culling. Involuntarily culled cows included dead cows or cows sold for slaughter because of health problems. The monthly marginal probabilities of involuntary culling were calculated by using the approach of van Arendonk (1985a). The probabilities were corrected for parity and lactation stage, but they were independent of milk yield potential and length of previous calving interval. Calculations used 2 input values: the prob-

Table 2. Monthly marginal probabilities of conception for various parities and lactation stages

\begin{tabular}{lcccccccc}
\hline & \multicolumn{7}{c}{ Month after calving } \\
\cline { 2 - 9 } Parity & 2 & 3 & 4 & 5 & 6 & 7 & 8 & 9 \\
\hline 1 & 0.23 & 0.41 & 0.50 & 0.47 & 0.48 & 0.47 & 0.45 & 0.45 \\
2 & 0.25 & 0.44 & 0.54 & 0.51 & 0.52 & 0.51 & 0.47 & 0.46 \\
3 & 0.26 & 0.46 & 0.56 & 0.52 & 0.54 & 0.52 & 0.48 & 0.46 \\
4 & 0.26 & 0.46 & 0.56 & 0.52 & 0.54 & 0.52 & 0.48 & 0.46 \\
5 & 0.25 & 0.44 & 0.54 & 0.51 & 0.52 & 0.51 & 0.47 & 0.46 \\
6 & 0.24 & 0.43 & 0.53 & 0.49 & 0.51 & 0.49 & 0.46 & 0.46 \\
7 & 0.24 & 0.42 & 0.51 & 0.48 & 0.49 & 0.48 & 0.45 & 0.45 \\
8 & 0.23 & 0.40 & 0.50 & 0.46 & 0.48 & 0.47 & 0.44 & 0.44 \\
9 & 0.22 & 0.38 & 0.47 & 0.44 & 0.45 & 0.45 & 0.42 & 0.43 \\
10 & 0.21 & 0.37 & 0.46 & 0.42 & 0.44 & 0.43 & 0.41 & 0.42 \\
11 & 0.20 & 0.35 & 0.43 & 0.40 & 0.42 & 0.41 & 0.39 & 0.40 \\
12 & 0.19 & 0.34 & 0.42 & 0.38 & 0.40 & 0.39 & 0.38 & 0.39 \\
\hline
\end{tabular}


Table 3. Monthly marginal probabilities of involuntary culling for various parities and lactation stages with a fixed calving interval of 12 mo

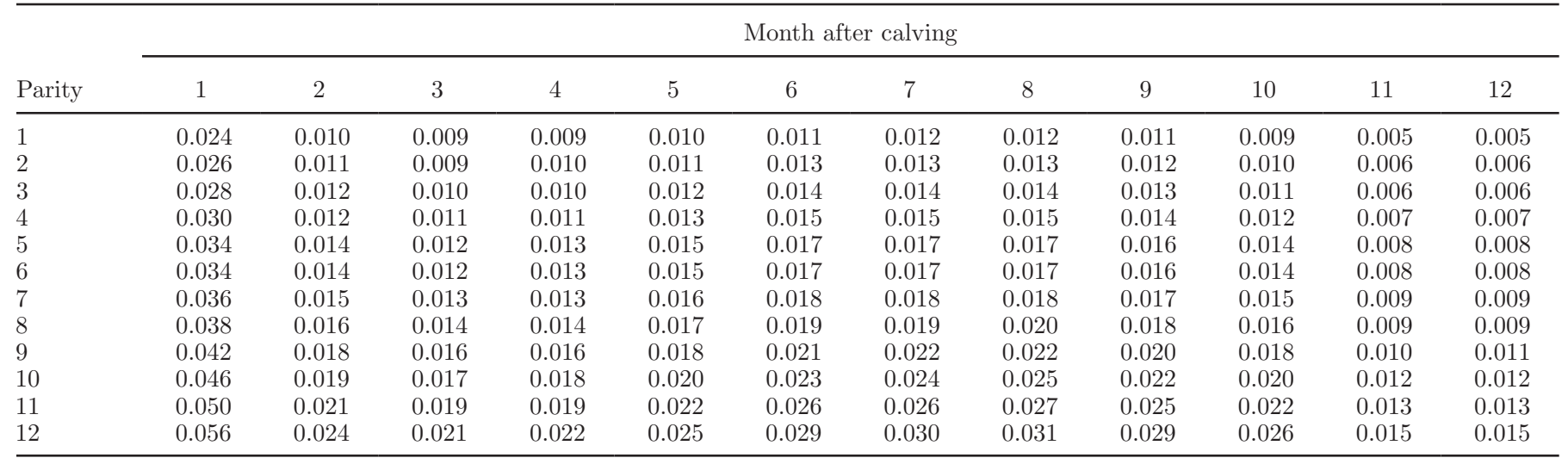

ability of involuntary culling during each parity and the monthly proportion of involuntary culling within each parity. To illustrate, monthly marginal probabilities of involuntary culling with a fixed calving interval of 12 mo are in Table 3.

Costs associated with involuntary culling included 3 items. First, a fixed cost of $€ 100$ per cow was assigned to the month of involuntary culling, accounting for additional veterinary treatments before removal (H. Hogeveen, Utrecht University, the Netherlands; personal communication). Second, milk yield was decreased for involuntarily culled cows in the month of removal. The loss in milk yield depended on parity and lactation stage, and was calculated by using the approach of van Arendonk (1985a). Because of lower milk yield, feed intake was decreased accordingly for involuntarily culled cows in the month of removal. The new feed ration was formulated by accounting for the decrease in total energy requirement for maintenance and milk production. Third, a fixed $10 \%$ loss in carcass value was assumed for involuntarily culled cows (H. Hogeveen, Utrecht University, the Netherlands; personal communication). This fixed reduction accounted for the fact that dead cows have no carcass value, cows with feet and leg problems have reduced carcass value, and cows with other health problems have virtually unchanged carcass value (van Arendonk et al., 1984).

Replacement Costs. We assumed fixed herd size; that is, a culled cow was immediately replaced. Replacement heifers were assumed to be 24 mo old and starting their first lactation. The replacement heifer price (Table 1) was independent of the heifer's milk yield potential.

\section{Mathematical Module}

In the mathematical module, the optimization problem for inseminations and replacements was modeled as an MLHMP (Kristensen and Jørgensen, 2000). This technique combines the properties of policy iteration and value iteration in a multi-level hierarchic manner. With MLHMP, detailed real-world applications with large state space can be solved with fast convergence and exact solutions. The model was programmed in Java and used as a plug-in to the MLHMP software system developed by Kristensen (2003). The MLHMP software was used to compute the optimal insemination and replacement policy, and then Markov chain simulations were performed to obtain whole-herd statistics following the optimal policy.

Model Structure. The model was constructed with 4 levels, and a graphical overview of the structure is given in Figure 2. At level 0, a single process (founder) existed with infinite time-horizon, where each stage represented the entire lifetime of a cow. Each stage of the founder process was expanded into a child process (child 1) at level 1. For each cow, therefore, the length of lifetime and the gained reward during her lifetime were determined by the corresponding child 1 process. The child 1 process was of finite time-horizon with a maximum of 12 stages, where each stage represented an entire lactation. Each stage of the child 1 process was then expanded into a child process (child 2) at level 2. Therefore, the length of the given lactation and the generated reward during that lactation were determined by the corresponding child 2 process. The child 2 process was of finite time-horizon with a maximum of 18 stages. The meaning of a stage at level 2 is 2 -fold, depending on pregnancy status during the lactation. As long as a cow was open, a stage represented a month in lactation. When a cow became pregnant, however, the consecutive stage represented the entire gestation period, which was then expanded into a child process (child 3) at level 3. Therefore, the length of the pregnancy and the reward during the pregnancy period were computed by the corresponding child 3 process. The child 3 process was of finite time-horizon with a maximum of 9 stages, where each stage represented a month $(30.5 \mathrm{~d})$ during pregnancy. 


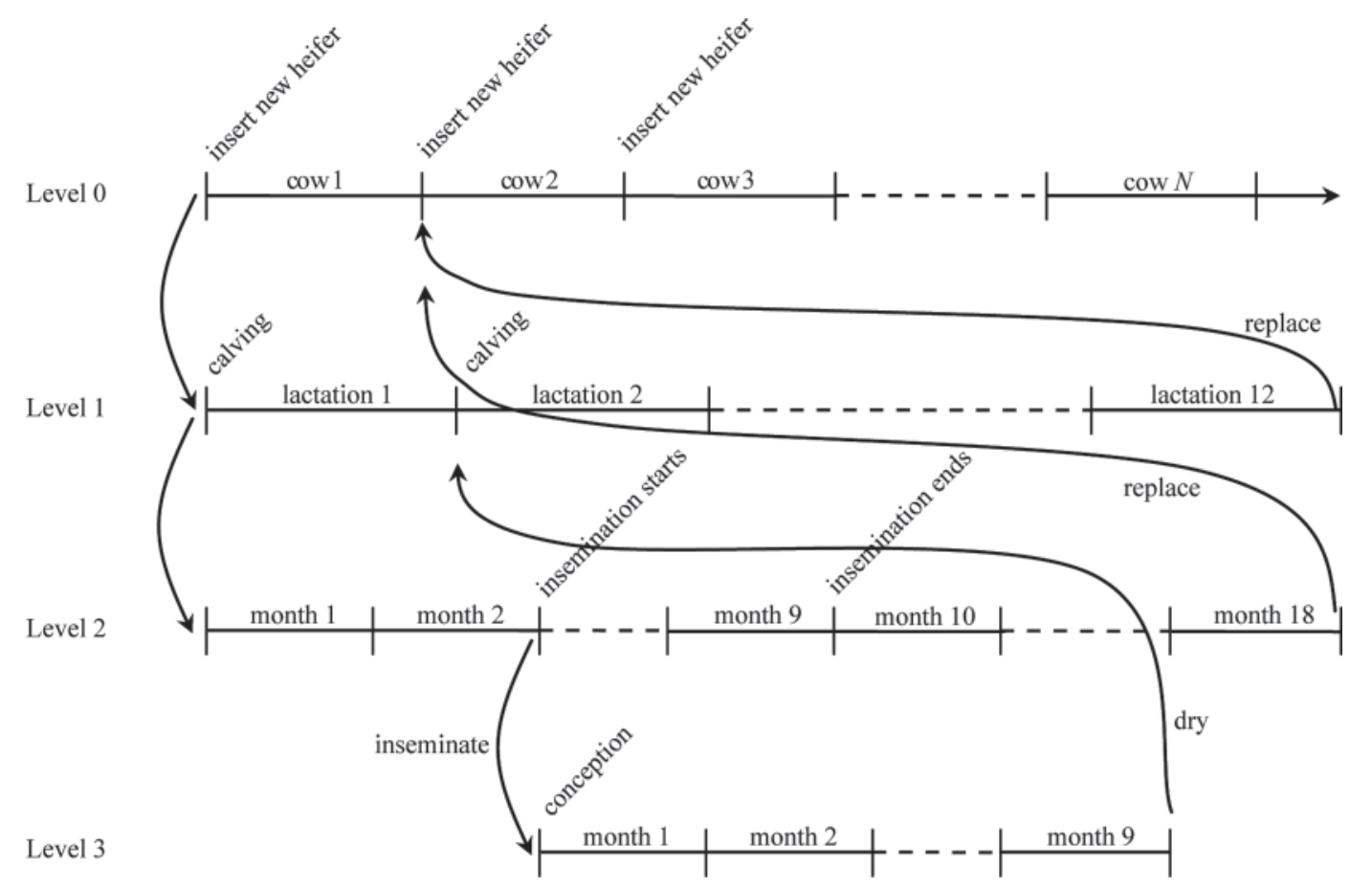

Figure 2. Schematic representation of the structure of the multi-level hierarchic Markov process model.

At each level, the state space could be described by 2 subsets of states. The first subset was the Cartesian product of one or more state variables. The second subset included additional states, which directly represented a cow. For the additional states, properties of an individual cow (e.g., yield class) were no longer relevant because she was replaced or diseased.

Discretizing the SSM. To embed the SSM into the MLHMP framework, the 2-dimensional space of the pair $\left(\hat{A}_{i, j, 1}, \hat{X}_{i, j, 1}\right)$ was discretized by using uniform discretization (Nielsen et al., 2011). The pair $\left(\hat{A}_{i, j, 1}, \hat{X}_{i, j, 1}\right)$ provided the necessary information to compute actual milk yield as described in equation [6]. Both variables were discretized separately into 13 intervals, with intervals having equal probabilities. We used 13 intervals because this definition of the state space led to robust results with acceptable computing time. In fact, however, the choice of 13 intervals was arbitrary. The model was constructed in a generic way, so that any number of intervals could be used. The partition was obtained by taking the cross product of the intervals obtained for each variable. It resulted in a total of 169 rectangles of equal probabilities, and each rectangle was represented by its corresponding mean.

States and Decisions at Level 0 . In the founder process, a single state variable was defined that reflected a permanent trait throughout the cow's lifetime.
The state variable at level 0 represented the cow's estimated permanent milk yield potential when entering the herd as heifer. Specifically, the state variable stored the value of $\hat{A}_{i, 0,0}$ from equation [4] for $i=1$. Because $\hat{A}_{1,0,0}$ was the expected value for $A \sim N\left(0, \sigma_{A}^{2}\right)$, the distribution was discretized to be stored in the MLHMP. The distribution was partitioned into 13 classes with equal probabilities. The state variable, therefore, had 13 levels. Only a dummy decision was defined at level 0 , representing that a new heifer was inserted into the herd. The estimated permanent milk yield potential of a new heifer was independent of that of the preceding cow. Because the founder process was of infinite timehorizon, each stage had identical state and action spaces. In each stage, therefore, a cow could take any of the 13 levels of the state variable.

States and Decisions at Level 1. In the child 1 process, state variables represented traits that were permanent during an entire lactation (including dry period). We defined 2 state variables at level 1 . The first variable represented the updated knowledge about the cow's permanent milk yield potential at the beginning of the lactation. That is, the first state variable stored the value of $\hat{A}_{i, 0,0}$ from equation [4] for $i>1$, where for $i=1$ the value was equal to the state at level 0 . Because $\hat{A}_{i, 0,0}$ was the expected value for $A \sim N\left(0, \sigma_{A}^{2}\right)$, the distribution was partitioned into 13 
levels with equal probabilities. The second state variable represented the number of open months in the previous lactation. The second variable was defined with 8 levels, allowing the open period to be minimum 2 mo and maximum 9 mo. Only a dummy decision was defined at level 1, representing that the cow started a new lactation. The state space at level 1 depended on the lactation. In the first lactation, a cow could have any of the 13 levels of the first state variable, but could not have a value for the second state variable (because there was no previous lactation yet). In later lactations, however, a cow could take any combination of the state variables, resulting in total possible states of $13 \times 8=$ 104.

States and Decisions at Level 2. In the child 2 process, state variables represented traits that were permanent during a month in lactation. We defined 2 state variables and 1 additional state. The first state variable represented the cow's actual milk yield in the given month. The variable stored the value of the pair $\left(\hat{A}_{i, j, 1}, \hat{X}_{i, j, 1}\right)$, which was equivalent to $\mathbf{m}_{i, j, 1}$ from equation [5]. Because $\mathbf{m}_{i, j, 1}$ was the mean of a multivariate normal distribution, its value was discretized. We used a uniform discretization with 13 levels for the pair $\left(\hat{A}_{i, j, 1}, \hat{X}_{i, j, 1}\right)$ as described earlier, resulting in $13 \times 13=$ 169 levels. The second state variable was a binary variable representing pregnancy state (pregnant or nonpregnant). In addition to the 2 state variables, a single state was included to represent that the cow was involuntarily culled.

At level 2, 3 decisions were defined: replace the cow immediately with a calving heifer, keep the cow for another month without insemination, or inseminate the cow and keep her for another month. However, not every decision was allowed in every month in lactation. In the first month, only a dummy action was defined, representing that the cow started a new month in lactation. In the second month, 2 decisions were defined: keep the cow without insemination or inseminate and keep her for another month. From mo 3 to mo 9, all 3 decisions were allowed. When a decision to inseminate was made and the service was successful, the process at level 2 proceeded to the next stage, which was modeled as a child process at level 3 . From mo 10 through mo 18 , again 2 decisions were allowed: replace the cow immediately or keep the cow without insemination.

The possible state space for a cow at level 2 was dependent on the lactation stage. In mo 1 and mo 2, a cow could have any values for the actual milk production level or could be involuntarily culled $(169+1=$ 170). From mo 3 through mo 10, a cow could be open or pregnant. Therefore, the second state variable was added to the state space $(169 \times 2+1=339)$. When a cow became pregnant, the process continued at level 3 as discussed above. From mo 11, a cow could no longer be pregnant because no insemination was allowed in the previous month; thus, the state space was defined by the first state variable and the additional state for involuntary culling $(169+1=170)$.

States and Decisions at Level 3. In the child 3 process, the state variables represented traits that were permanent during the entire period of pregnancy. We defined one state variable and an additional state at level 3. The state variable was equivalent to the first state variable at level 2 . Therefore, it represented the cow's actual milk yield in the given month. The variable stored the value of the pair $\left(\hat{A}_{i, j, 1}, \hat{X}_{i, j, 1}\right)$, with $13 \times$ $13=169$ levels, as described earlier. The additional state represented that the cow was involuntarily culled. The decisions were uniform across the months of pregnancy. In each month, 2 decisions were defined: either replace the cow immediately with a calving heifer or keep the cow for another month. Because the same states and decisions were defined for each stage, the state space at level 3 was always defined by the state variable and the additional state $(169+1=170)$.

Transition Probabilities. The transition from one state in the current month to another state in the next month had a transition probability. When a cow was inseminated and kept for another month, the transition probability was defined by the transition between actual milk yield levels $\left(\boldsymbol{p}_{\text {prod }}\right)$, the transition into the state of being pregnant $\left(\boldsymbol{p}_{\text {preg }}\right)$, and the transition into the state of being involuntarily culled $\left(\boldsymbol{p}_{i n v}\right)$. When a cow was kept for another month without insemination, the transition probability was defined by $p_{\text {prod }}$ and $p_{i n v}$. The probability $p_{\text {prod }}$ was derived from the multivariate normal distribution in equation [8], as the integral of the density function in the intervals after discretizing the pair $\left(\hat{A}_{i, j, 1}, \hat{X}_{i, j, 1}\right)$. The probability $p_{\text {preg }}$ (Table 2 ) equaled the monthly marginal probability of conception, which was calculated by the bioeconomic module. The probability $p_{i n v}$ equaled the monthly marginal probability of involuntary culling, which was calculated by the bioeconomic module.

When a cow remained open after the insemination period, she was considered infertile and no longer inseminated. Such cow could be kept in the herd for a maximum of $18 \mathrm{mo}$, at which time she was replaced. In this case, the process at level 2 was terminated and returned to level 0 with probability 1 . Furthermore, when a decision to replace the cow immediately was made at level 2 or 3 , the process at the given level was immediately terminated and returned to level 0 with probability 1 . Similarly, when a cow entered the state of being involuntarily culled at level 2 or 3 , the 
process was immediately terminated and returned to level 0 with probability 1 . When a cow completed the pregnancy period at level 3 , the process was immediately terminated and returned to the next stage at level 1 with probability 1 , representing that the cow started the next lactation. When a cow completed the pregnancy period in the last parity, the process at level 3 was immediately terminated and returned to level 0 with probability 1 .

Rewards. The rewards of the model were equal to the expected discounted economic net revenue of a cow during a stage at a level in question, given all information available (i.e., level, stage, state, decision). At level 0 , the reward represented the expected net revenue of a cow during her lifetime minus the initial cost of purchasing the heifer, where the expected net revenue was calculated based on the child processes at lower levels. At level 1, the reward represented the expected net revenue of a cow during lactation plus the calf revenues, where the expected net revenue was calculated based on the child process(es) at lower level(s).

At level 2, the reward was dependent on pregnancy status. First, for an open cow, the reward represented the expected net revenue during a month in lactation. Under decision to replace immediately, the reward equaled the carcass revenue. Under decision to keep without insemination, the reward was calculated as follows: (milk revenue - feed cost - sundry cost) $\times$ $\left(1-p_{\text {inv }}\right)+($ milk revenue - feed cost - sundry cost + carcass revenue - cost of involuntary culling $) \times p_{i n v}$. Under decision to inseminate and keep, the reward was calculated as (milk revenue - feed cost - sundry cost - insemination cost $) \times\left(1-p_{\text {inv }}\right)+($ milk revenue feed cost - sundry cost - insemination cost + carcass revenue - cost of involuntary culling $) \times p_{i n v}$. Second, for a cow that has finished pregnancy and has calved, the reward represented the expected net revenue during pregnancy, which was calculated in the child 3 process.

At level 3, the reward per stage represented the expected net revenue during a month in pregnancy. For a pregnant cow under decision to replace immediately, the reward equaled the carcass revenue. For a pregnant cow under decision to keep, the reward was calculated as at level 2 under the decision to keep the cow without insemination. In our model, furthermore, it was assumed that the cow was set dry in the last 2 mo during pregnancy. In those dry months, the calculation of the reward under decision to keep excluded the milk revenues.

Optimization. An insemination and replacement policy provided a plan of which decision to take given the stage and the state of the cow. The optimal policy was found by maximizing the total expected discounted net revenues. A yearly discount rate of $5 \%$ was used.
Markov chain simulations were performed to obtain whole-herd statistics following the optimal policy. The optimization and simulation algorithms are described in details in Kristensen and Jørgensen (2000). The total number of possible states was $1,480,651$. This was remarkably lower than the state variables on the different levels would imply. The reduction was achieved by having only a single child process at a given level for all those states at the level above, that are, in fact, equal processes differing only in their initial transition probabilities. This technique was applied at level 0 , 1 , and 2, which resulted in considerable reduction of computational complexity. For example, if each state at level 0 had been modeled with a separate child process, the total number of possible states would have been approximately 13 times higher.

\section{Sensitivity Analyses}

The presented results focus on herd performance, resulting from optimal insemination and replacement decisions for individual cows. After running the base scenario (as described in Table 1), 3 groups of sensitivity analyses were performed in which a set of input and parameter values were increased and decreased proportionally by $20 \%$. Our objective was not to test alternatives that reflect reality, but to study model behavior under extreme settings.

The first group of sensitivity analyses validated model behavior under changes in key biological and price inputs that have been previously reported to have substantial effect (e.g., van Arendonk, 1985b; van Arendonk and Dijkhuizen, 1985; Rogers et al., 1988a,b). The following inputs were changed: monthly marginal probabilities of conception (Table 2), monthly marginal probabilities of involuntary culling (e.g., Table 3), mean mature 305-d milk yield (Table 1), and replacement heifer price (Table 1). The second group of sensitivity analyses assessed the effects of methodological contributions and new biological parameters. We evaluated the effects of changes in key input values that were used in the feed intake calculations and in the SSM, and have not been tested before. Tested input values for feed intake calculations included energy requirement for maintenance (equation [9]), feed intake capacity (equation [10]), and adjustment factor of feed intake capacity for permanent milk yield potential (equation [10]). Tested SSM input included the phenotypic variation coefficient of 305-d milk yield (Table 1). The effect of an additional level in the MLHMP structure (relative to earlier models) was discussed qualitatively. The third group of sensitivity analyses studied the effects of variation in milk yield among individual cows. Results were compared for various degrees of variation among 
cows (i.e., various number of classes specified for actual milk yield level). Our goal with the latter analyses was to illustrate the importance of variation among individual animals and its direct effect on model outcome.

\section{RESULTS AND DISCUSSION}

\section{Base Scenario}

The simulated annual culling rate was $28.4 \%$, resulting in an average productive herd life of 42.2 mo per cow (Table 4), which was 2 mo shorter than actual productive herd life in Dutch herds (CRV, 2009). Because we assumed heifers to be 24 mo old when starting their first lactation, the simulated average total herd life was $66.2 \mathrm{mo}$. In practice, however, the average age at first calving is $26 \mathrm{mo}$ and the average total herd life is $70 \mathrm{mo}$ (CRV, 2009). The simulated average calving interval was $396.5 \mathrm{~d}$, which was $18 \mathrm{~d}$ less than the average in the Netherlands (CRV, 2009). The difference might be because we did not model calving intervals longer than 18 mo, or because farmers make suboptimal insemination decisions. We found that $42.5 \%$ of all replacements were voluntary; that is, because of low production or failure to conceive. Our results suggest that farmers might operate with suboptimal calving intervals, whereas their culling rates are close to economic optimum under the modeled specifications.

Regarding technical and economic results (Table 4), the average monthly milk yield per cow was $734.6 \mathrm{~kg}$, with an average fat content of $4.28 \%$ and protein content of $3.48 \%$. This monthly milk yield resulted in average monthly milk revenue of $€ 257.6$ per cow. Average monthly total NE requirement per cow was $70 \mathrm{kVEM}$ per $100 \mathrm{~kg}$ of FPCM, and on average a cow was fed a monthly ration of $401.1 \mathrm{~kg}$ DM roughage and $156.6 \mathrm{~kg}$ DM concentrate. Mean feed cost per cow was $€ 8.6$ per $100 \mathrm{~kg}$ of FPCM, whereas average annual insemination cost was $€ 48.2$ per cow. The average monthly net revenue per cow was $€ 40$. A herd with 75 cows, which is the average herd size in the Netherlands (LEI, 2008), would therefore generate a total net revenue of around $€ 36,000$ annually, which represents the farmer's financial compensation for labor and management. This annual total net revenue was close to current average dairy farm income in the Netherlands (LEI, 2008).

In this study, we assumed that when a cow was culled, she was sold exclusively for slaughter and immediately replaced. These assumptions could have an effect on culling rate and net income. Regarding culling, Cardoso et al. (1999) found that when cows were also allowed to be sold for production to other farms at a higher price, annual culling rate increased from about 22 to $27 \%$. They also found that the average monthly net revenue per cow increased from US $\$ 66.9$ to US $\$ 67.4$ by introducing selling for production. Regarding replacement, De Vries (2004) examined the effect of allowing temporarily delayed replacement. He found that under typical farming conditions, delayed replacement was not economically advantageous. However, in situations where fixed costs and net returns were low and seasonality was high, delayed replacement was more advantageous than immediate replacement. In those cases, De Vries (2004) found that the annual replacement rate decreased and the net return per cow increased. Because in our model fixed costs were already high and seasonality in performance and price was excluded, it is reasonable to assume that delayed replacement would not be advantageous. van Arendonk (1986), however, found large effects of seasonality on optimal replacement in the Netherlands. An extension of our model with seasonality, thus, might find financial incentives for delayed versus immediate replacement.

\section{Sensitivity Analyses 1: Model Validation}

Regarding changes in conception probabilities (Table 4 ), an increase of $20 \%$ resulted in lower annual culling rate $(27.9 \%$ ), whereas a decrease of $20 \%$ resulted in higher annual culling rate (29.6\%). Lower conception probabilities resulted in more intense voluntary cullings (46\%) and longer average calving interval (405.3 d). Higher conception probabilities resulted in less intense voluntary cullings $(40.7 \%)$ and shorter average calving intervals $(391.9 \mathrm{~d})$. The probability of conception, therefore, affected optimal insemination decisions and voluntary culling intensity. Voluntary culling, in turn, influenced herd composition and herd performance. Regarding technical performance (i.e., yields, energy requirement, feed intake capacity, feed intake), lower conception probabilities led to decreased inputs and outputs, whereas higher conception probabilities led to increased inputs and outputs. Regarding economic performance (i.e., costs and revenues), results changed accordingly. Average monthly net revenue per cow, for example, decreased by $€ 3.3$ when conception probabilities were decreased and increased by $€ 1.7$ when conception probabilities were increased.

Regarding changes in involuntary culling probabilities (Table 4), an increase of $20 \%$ resulted in higher annual culling rate $(30.4 \%)$ and less intense voluntary cullings $(36.8 \%)$, whereas a decrease of $20 \%$ resulted in lower annual culling rate $(26.4 \%)$ and more intense voluntary cullings $(49.3 \%)$. Optimal insemination decisions were virtually unaffected by changes in involuntary culling, because the average calving interval and the proportion of long ( $\geq 14 \mathrm{mo}$ ) calving intervals hardly changed. Because voluntary culling was affected, herd composition 
Table 4. Technical and economic parameters describing optimal insemination and replacement policy for base scenario and sensitivity analyses 1 (i.e., changes in monthly marginal probability of conception, monthly marginal probability of involuntary culling, mean mature 305-d milk yield, and price of replacement heifer)

\begin{tabular}{|c|c|c|c|c|c|c|c|c|c|}
\hline \multirow[b]{2}{*}{ Parameter } & \multirow{2}{*}{$\begin{array}{l}\text { Base } \\
\text { scenario }\end{array}$} & \multicolumn{2}{|c|}{$\begin{array}{l}\text { Probability of } \\
\text { conception }\end{array}$} & \multicolumn{2}{|c|}{$\begin{array}{c}\text { Probability of } \\
\text { involuntary culling }\end{array}$} & \multicolumn{2}{|c|}{$\begin{array}{l}\text { Mean mature } 305-\mathrm{d} \\
\text { milk yield }\end{array}$} & \multicolumn{2}{|c|}{$\begin{array}{l}\text { Price of } \\
\text { replacement heifer }\end{array}$} \\
\hline & & $80 \%$ & $120 \%$ & $80 \%$ & $120 \%$ & $80 \%$ & $120 \%$ & $80 \%$ & $120 \%$ \\
\hline \multicolumn{10}{|l|}{$\begin{array}{l}\text { Results describing a herd with optimal } \\
\text { insemination and culling policies }\end{array}$} \\
\hline Productive herd life (mo/cow) & 42.2 & 40.5 & 43.1 & 45.5 & 39.5 & 45.9 & 39.3 & 35.1 & 48.1 \\
\hline Calving interval $^{1}(\mathrm{~d} /$ cow $)$ & 396.5 & 405.3 & 391.9 & 396.6 & 396.3 & 396.7 & 396.2 & 396.4 & 396.4 \\
\hline Cows with calving interval $\geq 14 \mathrm{mo}^{1}(\%)$ & 24.7 & 33.5 & 19.1 & 25.0 & 24.6 & 25.0 & 24.6 & 24.7 & 24.7 \\
\hline Annual total culling rate $(\%)$ & 28.4 & 29.6 & 27.9 & 26.4 & 30.4 & 26.2 & 30.6 & 34.2 & 25.0 \\
\hline Proportion of voluntary cullings ${ }^{2}(\%)$ & 42.5 & 46.0 & 40.7 & 49.3 & 36.8 & 37.4 & 46.6 & 52.4 & 34.3 \\
\hline \multicolumn{10}{|l|}{$\begin{array}{l}\text { Average technical results for a cow in a } \\
\text { herd with optimal insemination and culling }\end{array}$} \\
\hline Milk yield (kg/mo) & 734.6 & 726.6 & 738.1 & 742.0 & 727.4 & 580.9 & 889.6 & 750.4 & 721.5 \\
\hline Fat yield $(\mathrm{kg} / \mathrm{mo})$ & 31.4 & 31.2 & 31.6 & 31.7 & 31.2 & 24.9 & 38.1 & 32.1 & 30.9 \\
\hline Protein yield $(\mathrm{kg} / \mathrm{mo})$ & 25.6 & 25.3 & 25.7 & 25.8 & 25.3 & 20.2 & 31.0 & 26.1 & 25.1 \\
\hline Feed intake capacity $\left(\mathrm{SV}^{3} / \mathrm{mo}\right)$ & 479.3 & 477.9 & 479.8 & 482.6 & 476.1 & 478.5 & 479.9 & 480.1 & 478.2 \\
\hline Energy requirement $\left(\mathrm{kVEM}^{4} / \mathrm{mo}\right)$ & 536.3 & 532.3 & 538.0 & 540.0 & 532.7 & 459.5 & 615.3 & 543.5 & 530.2 \\
\hline Energy requirement $\left(\mathrm{kVEM} / 100 \mathrm{~kg}\right.$ of $\left.\mathrm{FPCM}^{5}\right)$ & 70.0 & 70.2 & 70.0 & 69.8 & 70.2 & 75.9 & 66.3 & 69.5 & 70.5 \\
\hline Roughage intake (kg of DM/mo) & 401.1 & 399.2 & 402.2 & 403.7 & 398.7 & 401.1 & 380.1 & 403.4 & 398.8 \\
\hline Concentrate intake ( $\mathrm{kg}$ of $\mathrm{DM} / \mathrm{mo})$ & 156.6 & 154.5 & 157.3 & 157.9 & 155.3 & 83.0 & 251.0 & 161.5 & 152.8 \\
\hline \multicolumn{10}{|l|}{$\begin{array}{l}\text { Average economic results for a cow in a } \\
\text { herd with optimal insemination and culling }\end{array}$} \\
\hline Milk revenue (€/mo) & 257.6 & 255.3 & 258.6 & 260.1 & 255.2 & 203.7 & 312.0 & 263.1 & 253.0 \\
\hline Feed cost $(€ / \mathrm{mo})$ & 66.0 & 65.5 & 66.3 & 66.5 & 65.6 & 54.1 & 79.3 & 67.1 & 65.2 \\
\hline Feed cost $(€ / 100 \mathrm{~kg}$ of $\mathrm{FPCM})$ & 8.6 & 8.6 & 8.6 & 8.6 & 8.6 & 8.9 & 8.5 & 8.6 & 8.7 \\
\hline Average slaughter value $(€)$ & 528.2 & 528.9 & 527.9 & 529.3 & 527.1 & 528.8 & 527.6 & 528.2 & 528.5 \\
\hline Insemination cost $(€ / y r)$ & 48.2 & 57.4 & 41.1 & 47.8 & 48.6 & 48.1 & 48.3 & 47.4 & 48.6 \\
\hline Total net revenue $(€ / \mathrm{mo})$ & 39.9 & 36.6 & 41.6 & 44.2 & 35.7 & 0.1 & 79.0 & 48.2 & 32.7 \\
\hline Total net revenue ( $€$ /lifetime) & $1,684.1$ & $1,481.9$ & $1,793.2$ & $2,010.1$ & $1,409.9$ & 4.0 & $3,102.1$ & $1,692.7$ & $1,571.2$ \\
\hline Total net revenue $(€ / 100 \mathrm{~kg}$ of $\mathrm{FPCM})$ & 5.2 & 4.8 & 5.4 & 5.7 & 4.7 & 0.0 & 8.5 & 6.2 & 4.3 \\
\hline \multicolumn{10}{|c|}{${ }^{1}$ Based on completed lactations. } \\
\hline${ }^{2}$ Includes cows that did not get pregnant during $t$ & inseminat & period. & & & & & & & \\
\hline \multicolumn{10}{|c|}{${ }^{3}$ Satiety value $(\mathrm{CVB}, 2007)$} \\
\hline \multirow{2}{*}{\multicolumn{10}{|c|}{${ }^{4}$ Dutch feed unit, equivalent to $6.9 \mathrm{MJ}$ of net energy. }} \\
\hline & & & & & & & & & \\
\hline
\end{tabular}


and herd performance were also affected by changes in involuntary culling probabilities. Technical and economic indicators increased for lower involuntary culling probabilities and decreased for higher involuntary culling probabilities. For example, less intense involuntary culling led to $€ 4.3$ higher average monthly net revenue per cow, whereas more intense involuntary culling led to $€ 4.2$ lower average monthly net revenue per cow.

Regarding changes in mean mature 305 -d milk yield (Table 4), an increase of $20 \%$ resulted in higher annual culling rate $(30.6 \%)$ and more intense voluntary replacement $(46.6 \%)$, whereas a decrease of $20 \%$ resulted in lower annual culling rate $(26.2 \%)$ and less intense voluntary replacement $(37.4 \%)$. Optimal insemination decisions, however, were virtually unaffected by the changes in mean mature 305-d milk yield. Because of the effects on voluntary culling intensity, changes had an effect on technical and economic indicators of herd performance. Higher mean mature 305-d milk yield, on the one hand, resulted in elevated average monthly milk yield (889.6 kg per cow), NE requirement (615.3 $\mathrm{kVEM}$ per cow), and concentrate intake (251 kg of DM per cow). Lower mean mature 305-d milk yield, on the other hand, resulted in decreased average monthly milk yield (580.9 kg per cow), NE requirement (459.5 kVEM per cow), and concentrate intake (83 kg of DM per cow). Accordingly, the average monthly net revenue per cow increased to $€ 79$ following a $20 \%$ increase and decreased to $€ 0.1$ following a $20 \%$ decrease in mean mature 305-d milk yield.

Regarding changes in prices, model outcomes were sensitive to prices of milk and carcass, whereas they were insensitive to prices of feed, calf, and insemination (results not shown). Changes in replacement heifer price had large effects (Table 4). Lower heifer price resulted in a more intense voluntary culling policy $(52.4 \%)$, whereas higher heifer price resulted in less intense voluntary culling (34.3\%). Annual total culling rate was more affected by decreased heifer price than by increased heifer price, reflecting the relatively high price of replacement heifers in the Netherlands. Specifically, results indicate that farmers tend to keep their cows as long as possible, and so further increase in heifer price had limited effect. Optimal insemination decisions were virtually not sensitive to changes in heifer price. Technical and economic results increased when heifer price was lower and decreased when heifer price was higher. Average monthly net revenue per cow, for example, increased by €8.3 for lower heifer price and decreased by $€ 7.2$ for higher heifer price. Our results for the sensitivity analyses on key biological and price inputs were in agreement with the results of earlier studies (e.g., van Arendonk and Dijkhuizen, 1985; Rogers et al., 1988a,b; Kalantari et al., 2010).

\section{Sensitivity Analyses 2: Effects of Methodological Contributions and New Biological Parameters}

Methodological contributions were incorporated in 2 main aspects. First, an additional level to the model hierarchy was introduced to obtain a more tractable structure. Second, we included a recently developed cattle feed intake model to obtain more precise predictions on feed costs. Furthermore, we applied novel (literature based) parameters in the SSM, which modeled milk yield and captured variation in milk yield potential among individual cows.

SSM Parameterization. The sensitivity of model outcomes to the phenotypic variation coefficient of milk yield was investigated (Table 5). This parameter directly influenced the variability of latent variables $A$ and $X$. Increased variation coefficient, on the one hand, resulted in more intense voluntary culling (46.8\%) and thus higher average monthly net revenue per cow (€43). Decreased variation coefficient, on the other hand, resulted in less intense voluntary culling $(36.7 \%)$ and thus lower average monthly net revenue per cow (€37.1). When phenotypic variation was greater, therefore, differences in milk yield among individual cows became greater, creating more opportunities for voluntary replacement that led to improved herd performance. When phenotypic variation was lower, however, differences in milk yield among individual cows became smaller, creating fewer opportunities for voluntary replacement that led to decreased herd performance. Results for changes in phenotypic variation coefficient of milk yield were analogous to earlier results for changes in mean mature 305-d milk yield, although the effects on model outcomes were less extreme.

Feed Intake Calculations. First, sensitivity to energy requirement for maintenance was tested (Table 5 ). When the maintenance requirement was changed, optimal insemination and culling policies were virtually unaffected. Feed intake, however, was sensitive to changes in maintenance requirement. With an increased maintenance requirement, average monthly roughage and concentrate intakes per cow increased by $2.9 \mathrm{~kg}$ of DM and $29.9 \mathrm{~kg}$ of DM. With decreased maintenance requirements, however, average monthly roughage and concentrate intakes per cow decreased by $6.7 \mathrm{~kg}$ of DM and $26.5 \mathrm{~kg}$ of DM. Second, sensitivity to feed intake capacity was tested (Table 5). Changes in feed intake capacity hardly affected optimal insemination and replacement decisions, but they affected feed ration composition. When feed intake capacity was lowered, for example, average monthly intake per cow decreased by $104.5 \mathrm{~kg}$ of DM for roughage and increased by $92.5 \mathrm{~kg}$ of $\mathrm{DM}$ for concentrate. Third, sensitivity to the adjustment factor of feed intake capacity for per- 
manent milk yield potential was examined (Table 5). The results showed that model outcomes were virtually insensitive to changes in the adjustment factor. In conclusion, changes in maintenance requirement and feed intake capacity affected feed intake and therefore net revenues. Optimal insemination and replacement decisions, however, were insensitive to changes in feed intake calculations.

MLHMP Formulation. In this study, we introduced an additional level to the MLHMP structure to model the entire pregnancy process of a successfully inseminated cow. Because the pregnancy state of a pregnant cow was constant during the gestation period, it was represented by an additional child level. Introducing an additional level to the MLHMP structure was advantageous because it made the model structure more tractable for the end-user. The additional level, furthermore, lessens computational complexity by dividing transition matrices into smaller matrices that are handled one by one (Kristensen and Jørgensen, 2000). In our model, the transition matrices at level 2 were decreased. With the present 4-level structure, the size of the transition matrix was $339 \times 339$ from stage 3 through stage 10 and $170 \times 170$ in all other stages at level 2. If the pregnancy state was not modeled as a separate child process, then the state space at level 2 would need to be extended to properly account for the information about gestation stage. Such state extension would increase the size of the transition matrices to $1,700 \times 1,700$ throughout all stages at level 2 . Note, however, that other algorithms may result in the same computational time, regardless of the additional level in the MLHMP structure (see Nielsen and Kristensen, 2006).

\section{Sensitivity Analyses 3: Effects of the Number of Production Classes}

Although the variation in milk yield among individual cows is an important aspect of optimization models, the degree of variation has been rather neglected in the literature. To study the effect of the degree of variation, we ran the model with various numbers of classes for each state variable representing actual milk yield (Table 6). The tested number of classes ranged from 1 to 21 , with 13 being the default value for results presented in Tables 4 and 5.

Specifying more classes resulted in a convergence in several model outcomes. The proportion of voluntary replacements increased from 14 to $41 \%$ when the number of classes was increased from 1 to 5 , whereas it hardly changed beyond 13 classes. Optimal insemination decisions were virtually not affected, because the average calving interval and the share of long ( $\geq 14 \mathrm{mo})$ calving intervals hardly changed. Technical indicators improved when more classes were defined for milk yield. Average monthly milk yield per cow increased from $685.6 \mathrm{~kg}$ with 1 class to $735.9 \mathrm{~kg}$ with 21 classes. More classes also increased net revenue by providing more decisions to optimize. Average monthly net revenue per cow increased from €33.3 with 1 class to $€ 40.2$ with 21 classes. Benefits of a more refined state space for milk yield, however, were substantial at first but declined gradually with higher numbers of classes.

Specifying more classes, furthermore, greatly affected the total number of states, which ranged from 19,615 with 1 class to $3,835,955$ with 21 classes (Table 6). Increasing the number of milk yield classes increased computational complexity due to the "curse of dimensionality." Refining state space, therefore, soon becomes computationally prohibitive, even on modern computers. Consequently, a tradeoff exists between the number of milk yield classes and the overall state space in the MLHMP. Nielsen et al. (2011) suggested an iterative approach of stepwise refining the number of classes by a multivariate discretization technique and solving the MLHMP each time until an acceptable difference was achieved.

In the literature, several models have defined 15 classes for milk yield (e.g., van Arendonk, 1985b; Kristensen, 1987). Other examples, however, also exist, including those with 3 classes (Heikkilä et al., 2008), 5 classes (Kennedy and Stott, 1993; Bar et al., 2008), and 9 classes (Boichard, 1990). Until now, only McCullough and DeLorenzo (1996) assessed the effect of different number of milk yield classes. They tested the effects of various numbers of classes ranging from 3 to 15. On the one hand, they found that less variation resulted in lower average milk yield. This result agrees with our findings. On the other hand, they found that net revenue decreased with a greater number of classes. This finding disagrees with our results. Their findings, therefore, were inconsistent. Moreover, they reported effects on only a limited number of outputs and tested only a smaller number of classes than used in their base scenario.

\section{Applicability of the Model}

The traditional applications of herd optimization models can be grouped into 3 main clusters. First, models have been developed to aid farmers and herd improvement organizations in insemination and culling decisions (e.g., van Arendonk, 1988). Our model may be used to develop general management guidelines, by computing insemination value (IV) and retention payoff (RPO) for individual cows (Houben et al., 1994). The IV represents the expected extra profit from in- 
Table 6. Technical and economic parameters describing optimal insemination and replacement policy for sensitivity analyses 3 (i.e., different number of milk yield classes)

\begin{tabular}{|c|c|c|c|c|c|c|}
\hline Parameter & 1 class & 5 classes & 9 classes & 13 classes $^{1}$ & 17 classes & 21 classes \\
\hline \multicolumn{7}{|l|}{$\begin{array}{l}\text { Results describing a herd with optimal } \\
\text { insemination and culling policies }\end{array}$} \\
\hline Productive herd life (mo/cow) & 62.2 & 43.3 & 42.1 & 42.2 & 42.3 & 42.2 \\
\hline Calving interval $^{2}(\mathrm{~d} /$ cow $)$ & 396.4 & 396.5 & 396.6 & 396.5 & 396.4 & 396.5 \\
\hline Cows with calving interval $\geq 14 \mathrm{mo}^{2}(\%)$ & 25.0 & 25.0 & 25.0 & 24.7 & 24.7 & 24.8 \\
\hline \multicolumn{7}{|l|}{$\begin{array}{l}\text { Average technical results for a cow in a herd } \\
\text { with optimal insemination and culling }\end{array}$} \\
\hline Milk yield $(\mathrm{kg} / \mathrm{mo})$ & 685.6 & 726.7 & 733.3 & 734.6 & 735.3 & 735.9 \\
\hline Fat yield $(\mathrm{kg} / \mathrm{mo})$ & 29.3 & 31.1 & 31.4 & 31.4 & 31.5 & 31.5 \\
\hline Protein yield (kg/mo) & 23.8 & 25.3 & 25.5 & 25.6 & 25.6 & 25.6 \\
\hline Feed intake capacity $\left(\mathrm{SV}^{4} / \mathrm{mo}\right)$ & 473.7 & 477.9 & 479.0 & 479.3 & 479.4 & 479.6 \\
\hline \multicolumn{7}{|l|}{$\begin{array}{l}\text { Average economic results for a cow in a herd } \\
\text { with optimal insemination and culling }\end{array}$} \\
\hline Milk revenue $(€ / \mathrm{mo})$ & 240.1 & 254.8 & 257.1 & 257.6 & 257.9 & 258.1 \\
\hline Feed cost $(€ / \mathrm{mo})$ & 62.6 & 65.5 & 65.9 & 66.0 & 66.1 & 66.1 \\
\hline Feed cost $(€ / 100 \mathrm{~kg}$ of FPCM $)$ & 8.8 & 8.6 & 8.6 & 8.6 & 8.6 & 8.6 \\
\hline Average slaughter value $(€)$ & 530.2 & 528.4 & 528.3 & 528.2 & 528.2 & 528.2 \\
\hline Insemination cost $(€ / \mathrm{yr})$ & 49.7 & 47.4 & 47.9 & 48.2 & 48.4 & 48.3 \\
\hline Total net revenue $(€ / \mathrm{mo})$ & 33.3 & 38.3 & 39.5 & 39.9 & 40.1 & 40.2 \\
\hline Total net revenue ( $€$ /lifetime) & $2,070.3$ & $1,656.5$ & $1,660.5$ & $1,684.1$ & $1,695.4$ & $1,697.5$ \\
\hline Total net revenue $(€ / 100 \mathrm{~kg}$ of $\mathrm{FPCM})$ & 4.7 & 5.1 & 5.2 & 5.2 & 5.2 & 5.2 \\
\hline
\end{tabular}

${ }^{1}$ Results with 13 classes refer to the base scenario.

${ }^{2}$ Based on completed lactations.

${ }^{3}$ Includes cows that did not get pregnant during the insemination period.

${ }^{4}$ Satiety value (CVB, 2007).

${ }^{5}$ Dutch feed unit, equivalent to $6.9 \mathrm{MJ}$ of net energy.

${ }^{6}$ Fat- and protein-corrected milk.

seminating a cow compared with leaving her open. The RPO represents the expected extra profit from keeping a cow compared with immediate culling. The IV and RPO can be used to rank individual cows in insemination and replacement decisions (Kristensen, 1987; van Arendonk, 1988). Our model, moreover, can provide useful information for veterinary treatment decisions. Although the model does not have decisions about when to treat a cow, the RPO values represent the maximum amount of money that could be spent on trying to keep a cow. The RPO, therefore, gives the maximum acceptable treatment cost above which it is more profitable to cull a cow (van Arendonk, 1988).

Second, our model may be applied to study economics of animal health. Several earlier studies used herd optimization models to assess technical and economic effects of various diseases, including mastitis (Houben et al., 1994), paratuberculosis (Stott et al., 2005), lameness (Cha et al., 2010), and other cattle diseases (Gröhn et al., 2003). Our model can be useful in studying diseases, on condition that the model is extended for the examined diseases. Specifically, the state space needs to be extended to capture that a cow became diseased, and the bioeconomic module needs to be extended to account for the effect of the diseases on biological functions. The model can reoptimize insemination and culling decisions, ensuring that effects of the diseases are properly accounted for. Then, postoptimization simulations can be used to compare herd performance under the base (i.e., uninfected) and the diseased scenarios. The comparison can not only unravel the effects of diseases (e.g., Stott et al., 2002; Gröhn et al., 2003; Bar et al., 2008) but also be used to determine the economic value of various treatment and prevention options (e.g., Yalcin and Stott, 2000; Bar et al., 2009).

Third, the model presented in this study may be used to investigate the economic weight of selection traits in breeding programs for dairy cattle. Herd optimization 
models provide a proper framework for such objectives (Dekkers, 1991), and several earlier applications have been reported that examine the economic weight of selection traits. Studied selection traits include longevity (Rogers et al., 1988b; Stott, 1994), functional herd life (Jairath et al., 1998; Vollema et al., 2000), fertility (Boichard, 1990; Plaizier et al., 1997), and yield traits (Dekkers, 1991; Veerkamp et al., 1995). The present model can be used to derive the economic weight of selection traits from the individual producer's viewpoint. Our model can optimize the production system both in the base situation and after the change in genetic merit for the studied trait. This step ensures that the possible effects of the change in the studied trait on milk production, fertility, and longevity are incorporated. Then, Markov chain simulations can be applied to calculate the economic value as the change in the discounted net revenues following a unit increase in the goal trait concerned, while keeping all other traits constant.

In addition to the 3 main clusters outlined above, recently novel applications have emerged that evaluated the effect of various feeding regimens. Vargas et al. (2001) assessed the effect on optimal culling patterns and herd performance of several feeding regimens, which differed in type of forage for grazing, quantity of concentrates, and allocation of concentrates during lactation. Cabrera (2010) investigated not only the technical and economic effects of various diets, but also their environmental effects. Cabrera's herd optimization model was extended with environmental functions for manure and nutrition balance of the dairy herd, and average monthly nitrogen excretion per cow was computed. In conclusion, herd optimization and simulation models are versatile and valuable research tools for interdisciplinary studies. By applying the present model, various aspects of dairy farming systems can be investigated, including farm decision support, animal health economics, animal breeding, animal nutrition, and ecological sustainability. We anticipate that the model presented in this paper will be used primarily in research and extension in the future.

\section{CONCLUSIONS}

Our objective was to develop a dairy herd optimization and simulation model. The model incorporated methodological developments in 2 main aspects. First, our model was the first to formulate the dairy optimization problem as a 4-level hierarchic Markov process. Relative to earlier 3-level models, we introduced an additional level to model the pregnancy period, thereby obtaining a more tractable structure. Second, we incorporated a recently developed cattle feed intake model to obtain more precise predictions on feed costs. Fur- thermore, we presented a novel parameterization of the SSM for milk yield, and we used several new biological parameters to reflect the current cattle population. Results were generated under Dutch farming conditions, and outcomes were in line with actual herd performance in the Netherlands. Sensitivity analyses showed that greater variation in milk yield leads to more intense culling and higher net revenue. Energy requirements for maintenance and feed intake capacity did not influence optimal herd composition, whereas they did affect feed intake and economic results. Specifying more production classes increased net revenues by providing more decisions to optimize. Benefits of more classes were substantial at first but then gradually declined with higher number of classes. Future research may extend the model with environmental functions to investigate the ecological footprint of various farming settings.

\section{ACKNOWLEDGMENTS}

This study is part of the Dutch Milk Genomics Initiative and the project "Melk op Maat," funded by Wageningen University (Wageningen, the Netherlands), the Dutch Dairy Association (NZO, Zoetermeer, the Netherlands), the cooperative cattle improvement organization CRV (Arnhem, the Netherlands), the Dutch Technology Foundation (STW, Utrecht, the Netherlands), the Dutch Ministry of Economic Affairs (The Hague, the Netherlands), and the Provinces of Gelderland (Arnhem, the Netherlands) and Overijssel (Zwolle, the Netherlands). The authors thank Erwin Koenen and René van der Linde (CRV, Arnhem, the Netherlands) for providing biological input values, Paul Berentsen (Wageningen University, Wageningen, the Netherlands) for the help with prices, and H. Hogeveen (Utrecht University, Utrecht, the Netherlands) for the assistance with health-related issues.

\section{REFERENCES}

Arbel, R., Y. Bigun, E. Ezra, H. Sturman, and D. Hojman. 2001. The effect of extended calving intervals in high lactating cows on milk production and profitability. J. Dairy Sci. 84:600-608.

Bar, D., L. W. Tauer, G. Bennett, R. N. Gonzalez, J. A. Hertl, Y. H. Schukken, H. F. Schulte, F. L. Welcome, and Y. T. Gröhn. 2008 The cost of generic clinical mastitis in dairy cows as estimated by using dynamic programming. J. Dairy Sci. 91:2205-2214.

Bar, D., L. W. Tauer, G. Bennett, R. N. Gonzalez, J. A. Hertl, H. F. Schulte, Y. H. Schukken, F. L. Welcome, and Y. T. Gröhn. 2009. Use of a dynamic programming model to estimate the value of clinical mastitis treatment and prevention options utilized by dairy producers. Agric. Syst. 99:6-12.

Ben-Ari, Y., I. Amir, and S. Sharar. 1983. Operational replacement decision model for dairy herds. J. Dairy Sci. 66:1747-1759.

Ben-Ari, Y., and S. Gal. 1986. Optimal replacement policy for multicomponent systems: An application to a dairy herd. Eur. J. Oper. Res. 23:213-221.

Bohmanova, J., J. Jamrozik, and F. Miglior. 2009. Effect of pregnancy on production traits of Canadian Holstein cows. J. Dairy Sci 92:2947-2959. 
Boichard, D. 1990. Estimation of the economic value of conception rate in dairy cattle. Livest. Prod. Sci. 24:187-204.

Brotherstone, S., R. Thompson, and I. M. S. White. 2004. Effects of pregnancy on daily milk yield of Holstein-Friesian dairy cattle. Livest. Prod. Sci. 87:265-269.

Cabrera, V. E. 2010. A large Markovian linear program to optimize replacement policies and dairy herd net income for diets and nitrogen excretion. J. Dairy Sci. 93:394-406.

Cardoso, V. L., J. R. Nogueira, and J. A. M. Van Arendonk. 1999. Optimal replacement and insemination policies for Holstein cattle in the southeastern region of Brazil: The effect of selling animals for production. J. Dairy Sci. 82:1449-1458.

Cha, E., J. A. Hertl, D. Bar, and Y. T. Gröhn. 2010. The cost of different types of lameness in dairy cows calculated by dynamic programming. Prev. Vet. Med. 97:1-8.

CRV. 2009. Jaarstatistieken 2008 (Annual Statistics 2008). CRV, Arnhem, the Netherlands.

CVB. 2007. CVB-tabel herkauwers 2007. Chemische samenstelling en nutritionele waarden van voedermiddelen en voedernormen. (CVB-table ruminants 2007. Chemical composition and nutritional values of feedstuffs and requirement values) (in Dutch). CVBreeks nr. 31. Central Bureau for Livestock Feeding, The Hague, the Netherlands.

De Vries, A. 2004. Economics of delayed replacement when cow performance is seasonal. J. Dairy Sci. 87:2947-2958.

Dekkers, J. C. M. 1991. Estimation of economic values for dairy cattle breeding goals: Bias due to sub-optimal management policies. Livest. Prod. Sci. 29:131-149.

Fetrow, J., K. V. Nordlund, and H. D. Norman. 2006. Invited review: Culling: Nomenclature, definitions, and recommendations. J. Dairy Sci. 89:1896-1905.

Giaever, H. B. 1966. Optimal dairy cow replacement policies. PhD Thesis. University of California, Berkeley.

Gröhn, Y. T., P. J. Rajala-Schultz, H. G. Allore, M. A. DeLorenzo, J. A. Hertl, and D. T. Galligan. 2003. Optimizing replacement of dairy cows: Modeling the effects of diseases. Prev. Vet. Med. $61: 27-43$

Heikkilä, A. M., J. I. Nousiainen, and L. Jauhiainen. 2008. Optimal replacement policy and economic value of dairy cows with diverse health status and production capacity. J. Dairy Sci. 91:2342-2352.

Houben, E. H. P., R. B. M. Huirne, A. A. Dijkhuizen, and A. R. Kristensen. 1994. Optimal replacement of mastitic cows determined by a hierarchic Markov process. J. Dairy Sci. 77:2975-2993.

Inchaisri, C., R. Jorritsma, P. L. A. M. Vos, G. C. van der Weijden, and H. Hogeveen. 2010. Economic consequences of reproductive performance in dairy cattle. Theriogenology 74:835-846.

Jairath, L., J. C. M. Dekkers, L. R. Schaeffer, Z. Liu, E. B. Burnside, and B. Kolstad. 1998. Genetic evaluation for herd life in Canada. J. Dairy Sci. 81:550-562.

Jalvingh, A. W., J. A. M. van Arendonk, and A. A. Dijkhuizen. 1993. Dynamic probabilistic simulation of dairy herd management practices. I. Model description and outcome of different seasonal calving patterns. Livest. Prod. Sci. 37:107-131.

Kalantari, A. S., H. Mehrabani-Yeganeh, M. Moradi, A. H. Sanders, and A. D. Vries. 2010. Determining the optimum replacement policy for Holstein dairy herds in Iran. J. Dairy Sci. 93:2262-2270.

Kennedy, J. O. S., and A. W. Stott. 1993. An adaptive decision-making aid for dairy cow replacement. Agric. Syst. 42:25-39.

Korver, S., J. A. M. Van Arendonk, and W. J. Koops. 1985. A function for live weight change between two calvings in dairy cattle. Anim. Prod. 40:233-241.

Kristensen, A. R. 1987. Optimal replacement and ranking of dairy cows determined by a hierarchic Markov process. Livest. Prod. Sci. 16:131-144.

Kristensen, A. R. 1988. Hierarchic Markov processes and their applications in replacement models. Eur. J. Oper. Res. 35:207-215.

Kristensen, A. R. 1989. Optimal replacement and ranking of dairy cows under milk quotas. Acta Agric. Scand. 39:311-318.

Kristensen, A. R. 1991. Maximization of net revenue per unit of physical output in Markov decision processes. Eur. Rev. Agric. Econ. 18:231-244.
Kristensen, A. R. 1992. Optimal replacement in the dairy herd: A multi-component system. Agric. Syst. 39:1-24.

Kristensen, A. R. 1994. A survey of Markov decision programming techniques applied to the animal replacement problem. Eur. Rev. Agric. Econ. 21:73-93.

Kristensen, A. R. 2003. A general software system for Markov decision processes in herd management applications. Comput. Electron. Agric. 38:199-215.

Kristensen, A. R., and E. Jørgensen. 2000. Multi-level hierarchic Markov processes as a framework for herd management support. Ann. Oper. Res. 94:69-89.

KWIN. 2009. Kwantitatieve Informatie Veehouderij 2009-2010 (Quantitative Information in Animal Husbandry) (in Dutch). Research Institute for Animal Husbandry, Lelystad, the Netherlands.

Lehenbauer, T. W., and J. W. Oltjen. 1998. Dairy cow culling strategies: Making economical culling decisions. J. Dairy Sci. 81:264271

LEI. 2008. Farm Accountancy Data Network. Accessed October 12, 2010. http://www.lei.wur.nl/UK/statistics/Binternet/.

McCullough, D. A. and M. A. DeLorenzo. 1996. Evaluation of a stochastic dynamic replacement and insemination model for dairy cattle. J. Dairy Sci. 79:50-61.

Mourits, M. C. M., R. B. M. Huirne, A. A. Dijkhuizen, A. R. Kristensen, and D. T. Galligan. 1999. Economic optimization of dairy heifer management decisions. Agric. Syst. 61:17-31.

Nielsen, L. R., E. Jørgensen, and S. Højsgaard. 2011. Embedding a state space model into a Markov decision process. Ann. Oper. Res. 190:289-309. doi:10.1007/s10479-010-0688-z.

Nielsen, L. R., E. Jørgensen, A. R. Kristensen, and S. Østergaard. 2010. Optimal replacement policies for dairy cows based on daily yield measurements. J. Dairy Sci. 93:75-92.

Nielsen, L. R., and A. R. Kristensen. 2006. Finding the K best policies in a finite-horizon Markov decision process. Eur. J. Oper. Res. 175:1164-1179.

Olori, V. E., S. Brotherstone, W. G. Hill, and B. J. McGuirk. 1997. Effect of gestation stage on milk yield and composition in Holstein Friesian dairy cattle. Livest. Prod. Sci. 52:167-176.

Oltenacu, P. A., T. R. Rounsaville, R. A. Milligan, and R. L. Hintz. 1980. Relationship between days open and cumulative milk yield at various intervals from parturition for high and low producing cows. J. Dairy Sci. 63:1317-1327.

Österman, S., and J. Bertilsson. 2003. Extended calving interval in combination with milking two or three times per day: Effects on milk production and milk composition. Livest. Prod. Sci. 82:139 149

Plaizier, J. C. B., G. J. King, J. C. M. Dekkers, and K. Lissemore. 1997. Estimation of economic values of indices for reproductive performance in dairy herds using computer simulation. J. Dairy Sci. 80:2775-2783.

Rehn, H., B. Berglund, U. Emanuelson, G. Tengroth, and J. Philipsson. 2000. Milk production in Swedish dairy cows managed for calving intervals of 12 and 15 months. Acta Agric. Scand. Anim. Sci. 50:263-271.

Rogers, G. W., J. A. M. van Arendonk, and B. T. McDaniel. 1988a. Influence of production and prices on optimum culling rates and annualized net revenue. J. Dairy Sci. 71:3453-3462.

Rogers, G. W., J. A. M. van Arendonk, and B. T. McDaniel. 1988b. Influence of involuntary culling on optimum culling rates and annualized net revenue. J. Dairy Sci. 71:3463-3469.

Sadek, M. H., and A. E. Freeman. 1992. Adjustment factors for previous and present days open considering all lactations. J. Dairy Sci. $75: 279-287$.

Schils, R. L. M., M. H. A. de Haan, J. G. A. Hemmer, A. van den Polvan Dasselaar, J. A. de Boer, A. G. Evers, G. Holshof, J. C. van Middelkoop, and R. L. G. Zom. 2007. DairyWise, a whole-farm dairy model. J. Dairy Sci. 90:5334-5346.

Stewart, H. M., E. B. Burnside, J. W. Wilton, and W. C. Pfeiffer. 1977. A dynamic programming approach to culling decisions in commercial dairy herds. J. Dairy Sci. 60:602-617.

Stott, A. W. 1994. The economic advantage of longevity in the dairy cow. J. Agric. Econ. 45:113-122. 
Stott, A. W., G. M. Jones, G. J. Gunn, M. Chase-Topping, R. W. Humphry, H. Richardson, and D. N. Logue. 2002. Optimum replacement policies for the control of subclinical mastitis due to $S$. aureus in dairy cows. J. Agric. Econ. 53:627-644.

Stott, A. W., G. M. Jones, R. W. Humphry, and G. J. Gunn. 2005. Financial incentive to control paratuberculosis (Johne's disease) on dairy farms in the United Kingdom. Vet. Rec. 156:825-831.

van Arendonk, J. A. M. 1984. Studies on the replacement policies in dairy cattle. I. Evaluation of techniques to determine the optimum time for replacement and to rank cows on future profitability. Z. Tierzucht. Zuchtungs. 101:330-340.

van Arendonk, J. A. M. 1985a. A model to estimate the performance, revenues and costs of dairy cows under different production and price situations. Agric. Syst. 16:157-189.

van Arendonk, J. A. M. 1985b. Studies on the replacement policies in dairy cattle. II. Optimum policy and influence of changes in production and prices. Livest. Prod. Sci. 13:101-121.

van Arendonk, J. A. M. 1986. Studies on the replacement policies in dairy cattle. IV. Influence of seasonal variation in performance and prices. Livest. Prod. Sci. 14:15-28.

van Arendonk, J. A. M. 1988. Management guides for insemination and replacement decisions. J. Dairy Sci. 71:1050-1057.

van Arendonk, J. A. M. 1991. Use of profit equations to determine relative economic value of dairy cattle herd life and production from field data. J. Dairy Sci. 74:1101-1107.

van Arendonk, J. A. M., and A. A. Dijkhuizen. 1985. Studies on the replacement policies in dairy cattle. III. Influence of variation in reproduction and production. Livest. Prod. Sci. 13:333-349.

van Arendonk, J. A. M., P. E. Stokvisch, S. Korver, and J. K. Oldenbroek. 1984. Factors determining the carcass value of culled dairy cows. Livest. Prod. Sci. 11:391-400.

Van Bruggen, C. 2008. Dierlijke mest en mineralen 2008. (Animal manure and minerals 2008) (in Dutch). Centraal Bureau voor de Statistiek, Voorburg/Heerlen, the Netherlands.

Van Knegsel, A. T., H. Van den Brand, J. Dijkstra, W. M. van Straalen, M. J. W. Heetkamp, S. Tamminga, and B. Kemp. 2007. Dietary energy source in dairy cows in early lactation: Energy partitioning and milk composition. J. Dairy Sci. 90:1467-1476.

Vargas, B., M. Herrero, and J. A. M. van Arendonk. 2001. Interactions between optimal replacement policies and feeding strategies in dairy herds. Livest. Prod. Sci. 69:17-31.

Veerkamp, R. F., W. G. Hill, A. W. Stott, S. Brotherstone, and G. Simm. 1995. Selection for longevity and yield in dairy cows using transmitting abilities for type and yield. Anim. Sci. 61:189-197.

Vollema, A. R. S. Van Der Beek, A. G. F. Harbers, and G. De Jong. 2000. Genetic evaluation for longevity of Dutch dairy bulls. J. Dairy Sci. 83:2629-2639.

West, M., and J. Harrison. 1997. Bayesian Forecasting and Dynamic Models. 2nd ed. Springer Series in Statistics. Springer, New York, NY.

Wood, P. D. P. 1985. Importance of the calving interval to milk yield in the following lactation of British Friesian cows. J. Dairy Res. $52: 1-8$

Yalcin, C., and A. W. Stott. 2000. Dynamic programming to investigate financial impacts of mastitis control decisions in milk production systems. J. Dairy Res. 67:515-528.

Yates, C. M., and T. Rehman. 1998. A linear programming formulation of the Markovian decision process approach to modelling the dairy replacement problem. Agric. Syst. 58:185-201.

\section{APPENDIX}

\section{Calculation of Monthly Mean Milk Yield}

The mean milk yield was calculated by using the approach of van Arendonk (1985a). The starting point was the mean 305-d milk yield at mature age (7 yr) that was then corrected for the effect of parity. The mean 305-d milk yield in a given parity was calculated as

$$
m 305_{i}^{\text {milk }}=m 305_{\text {mature }}^{\text {milk }} \times a g e_{i}^{\text {milk }},
$$

where $m 305_{i}^{\text {milk }}$ was the mean 305 -d milk yield $(\mathrm{kg})$ in parity $i, m 305_{\text {mature }}^{\text {milk }}$ was the mean 305 -d milk yield (kg) at mature age, and $a g e_{i}^{\text {milk }}$ was the multiplicative effect of parity $i$ on mean 305-d milk yield. In the model, the value of $m 305_{\text {mature }}^{\text {milk }}$ was set to $9,000 \mathrm{~kg}$ based on information from cooperative cattle improvement organization CRV (Arnhem, the Netherlands). The values for $a g e_{i}^{\text {milk }}$ were also from CRV and are presented in Table 7.

Because in equation [11] the 305-d milk yield was calculated, the length of calving interval was implicitly assumed to be 12 mo. However, in our model we assumed that the calving interval could vary due to different number of open months (see the section on the mathematical module). Therefore, a correction was included for the length of calving interval in the present lactation. This correction resulted in the calculation of the mean lactation milk yield $(\mathrm{kg})$. The mean lactation milk yield was calculated from the following equation:

$$
\text { mlact }_{i, k}^{\text {milk }}=m 305_{i}^{\text {milk }} \times c i_{i, k}^{\text {pres }},
$$

where mlact $_{i, k}^{\text {milk }}$ was the mean lactation milk yield $(\mathrm{kg})$ in parity $i$ with $k$ months open in present lactation, and $c i_{i, k}^{\text {pres }}$ was the multiplicative effect in parity $i$ of $k$ months open in present lactation. Values for $c i_{i, k}^{\text {pres }}$ were calculated as follows. The lactation curve of van Arendonk (1985a) was adapted to include the effect of parity,

Table 7. Multiplicative adjustment factors ${ }^{1}$ for the effect of parities on mean 305-d milk yield, 305-d fat content, and 305-d protein content

\begin{tabular}{lccc}
\hline Parity & $\begin{array}{c}305-\mathrm{d} \\
\text { milk } \\
\text { yield }\end{array}$ & $\begin{array}{c}305-\mathrm{d} \\
\text { fat } \\
\text { content }\end{array}$ & $\begin{array}{c}305-\mathrm{d} \\
\text { protein } \\
\text { content }\end{array}$ \\
\hline 1 & 0.73 & 1.01 & 1.01 \\
2 & 0.86 & 1.01 & 1.02 \\
3 & 0.94 & 1.01 & 1.01 \\
4 & 0.99 & 1.01 & 1.00 \\
5 & 1.00 & 1.00 & 1.00 \\
6 & 1.00 & 1.00 & 1.00 \\
7 & 0.98 & 0.99 & 1.00 \\
8 & 0.94 & 0.98 & 0.99 \\
9 & 0.94 & 0.98 & 0.99 \\
10 & 0.94 & 0.98 & 0.99 \\
11 & 0.94 & 0.98 & 0.99 \\
12 & 0.94 & 0.98 & 0.99 \\
\hline
\end{tabular}

${ }^{1}$ Provided by the cooperative cattle improvement organization CRV (Arnhem, the Netherlands). 
lactation stage, and calving interval, and to exclude the effect of seasons. The resulting lactation curve is written as

$$
y_{t, k}=[a-b \times t-13 \exp (-c \times t)] /\left[1+(p / 140)^{2}\right],
$$

where $y_{t, k}$ was the daily milk yield $(\mathrm{kg})$ at $t$ days after calving and $k$ months open in present lactation, $a$ was the level parameter $(\mathrm{kg}), b$ was the slope during the decline in production after the peak production $(\mathrm{kg} / \mathrm{d})$, $c$ was the initial increase of production $(\mathrm{kg} / \mathrm{d})$, and $p$ was $t-(k \times 30.5-3.5)-122$ when $t \geq(k \times 30.5-$ $3.5)+122$, and 0 otherwise. Different values were used for parameters $a$ and $b$ during the first, second, and third or higher parities. The values were 22.0, 26.5, and 31.0 for parameter $a$, and $0.035,0.050$, and 0.065 for parameter $b$. The value of parameter $c$ was fixed at 0.125 . From the definition of parameter $p$, it follows that pregnancy was assumed to affect milk yield 4 mo (122 d) after conception. This assumption is in agreement with recent findings in various Holstein cattle breeds (see e.g., Olori et al., 1997; Brotherstone et al., 2004; Bohmanova et al., 2009).

To calculate the values for $c i_{i, k}^{\text {pres }}$ in equation [12], the lactation curve of equation [13] was fitted with different number of months open in present lactation. The value of $c i_{i, k}^{\text {pres }}$ for any $k$ was calculated as the ratio of total lactation yield from equation [13] assuming $k$ months open to total lactation yield from equation [13] assuming 3 mo open (which corresponds to the standard 12-mo-long calving interval). The absolute values of lactation yields from equation [13] were not used, but only the proportional change in lactation yield at different lengths of calving interval was computed. Because cows with longer calving interval (i.e., longer open period) tend to have a longer dry period (Oltenacu et al., 1980), the following formula was used to calculate the number of DIM at different open periods:

$$
D I M_{k}=222.65+0.9 \times(k \times 30.5),
$$

where $D I M_{k}$ was the realized total number of days in milk with $k$ months open in present lactation. Practically, by using the formula in equation [14], we imposed the assumption that an extra day open resulted in 0.9 extra days in milk, which is in line with recent findings on dairy cattle (Rehn et al., 2000; Arbel et al., 2001; Österman and Bertilsson, 2003). The obtained number of DIM from equation [14] was then incorporated in calculating $c i_{i, k}^{\text {pres }}$. The values of $c i_{i, k}^{\text {pres }}$ for different parities and open periods are presented in Table 8.

A consequence of equation [14] was that different calving intervals have different lengths of dry period. Because the dry period in turn influences the milk yield in the subsequent lactation (Wood, 1985), correction for previous calving interval was necessary when computing milk production in the present lactation. Therefore, equation [12] was extended as

$$
m l a c t_{i, k, l}^{\text {milk }}=m 305_{i}^{\text {milk }} \times c i_{i, k}^{\text {pres }} \times c i_{l}^{\text {prev }},
$$

where mlact $_{i, k, l}^{\text {milk }}$ is the mean lactation milk yield (kg) in parity $i$ with $k$ months open in present lactation and $l$ months open in previous lactation, and $c i_{l}^{\text {prev }}$ is the multiplicative effect of $l$ months open in previous lactation. Values for $c i_{l}^{\text {prev }}$ were derived from Sadek and Freeman (1992) and they are presented in Table 8. We used the same set of multiplicative factors for all parities, which is in line with the findings of Sadek and Freeman (1992).

Once the mean lactation milk yield was calculated, its value was distributed between monthly (30.5-d) periods to obtain the monthly mean milk yield. The lactation curve in equation [13] was used to calculate the proportions of the lactation yield at monthly intervals. To validate the obtained monthly shares of the lactation production, similar monthly percentages were

Table 8. Multiplicative adjustment factors for the effect of calving intervals in present ${ }^{1}$ and previous ${ }^{2}$ parities on mean 305-d milk yield

\begin{tabular}{lcccc}
\hline & \multicolumn{3}{c}{ Present calving interval } & $\begin{array}{c}\text { Previous } \\
\text { calving } \\
\text { Calving } \\
\text { interval (mo) }\end{array}$ \\
\cline { 2 - 5 } & Parity 1 & Parity 2 & Parity $\geq 3$ & 0.98 \\
\hline 11 & 0.93 & 0.94 & 0.94 & 1 \\
12 & 1 & 1 & 1 & 1.01 \\
13 & 1.07 & 1.06 & 1.05 & 1.02 \\
14 & 1.13 & 1.11 & 1.09 & 1.03 \\
15 & 1.18 & 1.15 & 1.13 & 1.04 \\
16 & 1.23 & 1.19 & 1.15 & 1.05 \\
17 & 1.27 & 1.21 & 1.18 & 1.05 \\
\hline
\end{tabular}

${ }^{1}$ Calculated by using equations [4] and [5].

${ }^{2}$ Based on Sadek and Freeman (1992). 
calculated by using a lactation curve from Schils et al. (2007), which is a recent lactation curve applied to Dutch Holstein cattle. The computed monthly percentages from their curve were in line with the percentages from our lactation curve (results not shown). Therefore, we concluded that the lactation curve of van Arendonk (1985a) is robust enough for computing the distribution of lactation production across months within lactation.

\section{Calculation of SSM Variance Parameters}

Variance parameters were obtained assuming a calving interval of $12 \mathrm{mo}$ and were used regardless the actual length of calving interval. The starting point for deriving the variance parameters was the mean 305-d milk yield at mature age $\left(m 305_{\text {mature }}^{\text {milk }}\right)$ from equation [11]. Furthermore, we assumed a coefficient of withinherd phenotypic variation $\left(V C_{305}\right)$ of $12 \%$ (van Arendonk, 1991). From $m 305_{\text {mature }}^{\text {milk }}$ and $V C_{305}$, we calculated the 305-d phenotypic variance at mature age $\left(\sigma_{P(305)}^{2}\right)$ as

$$
\sigma_{P(305)}^{2}=\left(V C_{305} \times m 305_{\text {mature }}^{\text {milk }}\right)^{2} .
$$

Then we assumed the following for decomposing the 305-d phenotypic variance:

$$
\sigma_{P(305)}^{2}=\sigma_{A(305)}^{2}+\sigma_{X(305)}^{2},
$$

where $\sigma_{A(305)}^{2}$ was the 305-d variance of $A\left(\mathrm{~kg}^{2}\right)$ from equation [2b], and $\sigma_{X(305)}^{2}$ was the $305-\mathrm{d}$ variance of $X_{i, j, t}$ $\left(\mathrm{kg}^{2}\right)$ from equation [2b]. Furthermore, we assumed the repeatability (r) of the 305-d yield to be 0.55 for consecutive lactations (van Arendonk, 1991). Because the term $A$ aggregates those effects on milk yield that are permanent features of the cow over lactations, the 305$\mathrm{d}$ variance in permanent milk yield potential $\left(\sigma_{A(305)}^{2}\right)$ could be derived as

$$
\sigma_{A(305)}^{2}=r \times \sigma_{P(305)}^{2},
$$

which in turn was used to calculate $\sigma_{X(305)}^{2}$ from equation [17]. Because the DLM in our model was constructed for daily yields, the 305 -d variances needed to be split up into daily variances $\sigma_{A}^{2}$ and $\sigma_{X}^{2}$. We assumed the following decomposition for $\sigma_{A(305)}^{2}$ and $\sigma_{X(305)}^{2}$ :

$$
\begin{gathered}
\sigma_{A(305)}^{2}=1 \times\left(\mathbf{H}_{305} \times \sigma_{A}^{2}\right) \times 1^{\prime}, \\
\sigma_{X(305)}^{2}=1 \times\left(\mathbf{H}_{305} \times \sigma_{X}^{2}\right) \times 1^{\prime},
\end{gathered}
$$

where $1=[305 \times 1]$ vector of $1 \mathrm{~s}, \mathbf{H}_{305}=[305 \times 305]$ autocorrelation matrix with $\mathrm{H}_{t, t^{*}}=\rho_{*}^{\left|t-t^{*}\right|}$, where $\rho_{*}$ was autocorrelation coefficient, and $t$ and $t^{*}$ were days since the beginning of the lactation. In equation [19a] the value of $\rho_{*}$ was equal to 1 , following the system equation of DLM in equation [3b], resulting in $\sigma_{A}^{2}$ of 6.90 $\mathrm{kg}^{2}$. In equation [19b] the value of $\rho_{*}$ was set equal to $\rho$ from the system equation of DLM in equation [3b]. The value of $\rho$ was assumed to be 0.98 (Nielsen et al., 2010a), resulting in $\sigma_{X}^{2}$ value of $20.74 \mathrm{~kg}^{2}$.

The last parameter to determine was $\sigma_{e_{1,0,0}}^{2}$ from equation [4], which was the distribution of $\hat{A}_{1,0,0}$ from equation [4]. The value of $\sigma_{e_{1,0,0}}^{2}$ represented the prior estimation uncertainty about $A$ that can be reduced through the Bayesian learning process based on later observations. When a cow is inserted to the herd as a heifer, the prior estimate $\left(\hat{A}_{1,0,0}\right)$ about her value for $A$ is based on her estimated genetic capacity for milk production. Therefore, the value of $\sigma_{e_{1,0.0}}^{2}$ is the conditional variance of the cow's $A$ value given the EBV for milk yield. In other words, $\sigma_{e_{1,0,0}}^{2}=V(A \mid E B V)$, specified as

$$
\begin{aligned}
V(A \mid E B V) & =V(B V+P E \mid E B V) \\
& =V(B V \mid E B V)+V(P E \mid E B V) \\
& =V(B V \mid E B V)+V(P E) \\
& =V(B V \mid E B V)+\sigma_{P E}^{2} .
\end{aligned}
$$

For the first term in equation [20], by using standard rules we have that

$$
V(B V \mid E B V)=\left(1-r_{I H}^{2}\right) \times V(B V)=\left(1-r_{I H}^{2}\right) \times \sigma_{B V}^{2},
$$

where $r_{I H}$ was the correlation between the true breeding value $(\mathbf{B V})$ and the $\mathrm{EBV}$, and $\sigma_{B V}^{2}$ is the daily variance of $\mathrm{BV}$. The value of $r_{I H}$ was 0.63 , whereas the value of $\sigma_{B V}^{2}$ was determined as

$$
\sigma_{B V}^{2}=h^{2} \times \sigma_{P}^{2}=\frac{h^{2}}{r} \times \sigma_{A}^{2},
$$

where $h^{2}$ was the heritability of milk yield with a value of $0.40, \sigma_{P}^{2}$ was the daily phenotypic variance of milk yield, $r$ was the repeatability of milk yield in consecutive lactations, and $\sigma_{A}^{2}$ was the daily variance of the permanent potential for milk yield from equation [19a]. For the second term in equation [20], because $\sigma_{A}^{2}=\sigma_{B V}^{2}+\sigma_{P E}^{2}$, we have that 


$$
\sigma_{P E}^{2}=\sigma_{A}^{2}-\sigma_{B V}^{2}=\sigma_{A}^{2}-\frac{h^{2}}{r} \times \sigma_{A}^{2}=\left(1-\frac{h^{2}}{r}\right) \times \sigma_{A}^{2}
$$

Consequently,

$$
\begin{aligned}
\sigma_{e_{1,0,0}}^{2} & =\left(1-r_{I H}^{2}\right) \times \frac{h^{2}}{r} \times \sigma_{A}^{2}+\left(1-\frac{h^{2}}{r}\right) \times \sigma_{A}^{2} \\
& =\left(1-r_{I H}^{2} \times \frac{h^{2}}{r}\right) \times \sigma_{A}^{2} .
\end{aligned}
$$

\section{Calculation of Monthly Fat and Protein Yields}

The calculations for both fat and protein yield can be divided into 3 steps: calculating the mean 305-d fat and protein content, calculating the monthly fat and protein content for given calving interval and age, and calculating the monthly fat and protein yield. In the first step, the mean 305-d fat and protein contents were calculated as

$$
\begin{aligned}
m 305_{i}^{f c} & =m 305_{\text {mature }}^{f c} \times a g e_{i}^{f c}, \\
m 305_{i}^{p c} & =m 305_{\text {mature }}^{p c} \times a g e_{i}^{p c},
\end{aligned}
$$

where $m 305_{i}^{f c}$ and $m 305_{i}^{p c}$ were the mean 305-d contents for fat and protein (\%) in parity $i, m 305_{\text {mature }}^{f c}$ and $m 305_{\text {mature }}^{p c}$ were the mean 305-d contents for fat and protein (\%) at mature age, and $a g e_{i}^{f c}$ and $a g e_{i}^{p c}$ were the multiplicative effects of parity $i$ on mean 305-d contents for fat and protein. Values of $m 305_{\text {mature }}^{f c}$ and $m 305_{\text {mature }}^{\text {pc }}$ were 4.25 and $3.45 \%$, respectively (from CRV). The $a g e_{i}^{f c}$ and $a g e_{i}^{p c}$ (provided by CRV) are shown in Table 7.

In the second step, the monthly fat and protein percentages were computed by satisfying 2 criteria. First, after weighting the monthly fat and protein percentages with the monthly relative productions (i.e., percentages derived during calculating the mean milk yield), they needed to average exactly to the mean 305-d contents from equations [25a] and [25b]. Second, because the lactation stage influences fat and protein contents, the monthly fat and protein percentages needed to have a changing pattern accordingly. In this model, the additive adjustment factors of van Arendonk (1985a) were used to account for the lactation stage.

Once the monthly percentages were computed, the realized monthly fat and protein yields were calculated in the third step as the product of the total monthly milk yield and the monthly percentage for fat and protein. Furthermore, regarding the effect of the length of previous calving interval, Sadek and Freeman (1992) found that the correction factors for fat production and for milk production were equal. This implies that the fat concentration was not influenced by the length of the previous calving interval. Consequently, in our model we assumed that the fat and protein contents were not affected by the previous calving interval.

\section{Calculation of FPCM Yield}

The average daily FPCM yield $\left(\right.$ adfpcm $\left._{i, j}\right)$ in equation [9] was calculated from (CVB, 2007)

$$
\text { adfpcm }_{i, j}=\frac{\left(\begin{array}{l}
0.337+0.116 \times \text { fat }_{i, j} \\
+0.060 \times \text { protein }_{i, j}
\end{array}\right) \times \text { milk }_{i, j}}{30.5},
$$

where $f a t \%_{i, j}$ was the fat percentage (\%) in month $j$ in parity $i$; protein $\%_{i, j}$ was the protein percentage (\%) in month $j$ in parity $i$; milk $k_{i, j}$ was the realized total milk yield $(\mathrm{kg})$ in month $j$ in parity $i$. To simplify the calculations, when the dry period started during month $j$, no separate calculation was made for the dry and the lactating parts for that particular month.

\section{Calculation of Live Weight}

The average live weight $\left(a l w_{i, j}\right)$ in equation [9] was determined as the average of the initial and final daily weights in month $j$. Those initial and final weights were calculated from the live weight function of Korver et al. (1985), as reported in van Arendonk (1985a):

$$
\begin{aligned}
l w_{t_{a}, t_{l}, t_{p}} & =A \times\left[1-\left\{1-\left(y_{0} \times A^{-1}\right)^{\frac{1}{3}}\right\} \times \exp \left(-k \times t_{a}\right)\right]^{3} \\
& -p_{1} \times t_{l} \times p_{2}^{-1} \times \exp \left(1-t_{l} \times p_{2}^{-1}\right)+p_{3}^{3} \times t_{p c}^{3}
\end{aligned}
$$

where $l w_{t_{a}, t_{l}, t_{p}}$ was the live weight $(\mathrm{kg})$ of a $t_{a}$-days-old cow at $t_{l}$ days in lactation and $t_{p}$ days pregnant; $t_{a}$ was the number of days since the birth of the cow; $t_{l}$ was the number of days since the last calving; $t_{p}$ was the number of days since conception; $A$ was the mature live weight $(\mathrm{kg}) ; y_{0}$ was the birth weight $(\mathrm{kg}) ; k$ was the growth rate parameter (per day), $p_{1}$ was the maximum decrease of live weight during the lactation $(\mathrm{kg}) ; p_{2}$ was the day after calving when the live weight is the lowest in the lactation; $p_{3}$ was pregnancy parameter (per day); and $t_{p c}$ was equal to $t_{p}-50$, when $t_{p}-50>0$, otherwise 0 . The value of $t_{a}$ at the start of a new lactation was the 
age in that parity assuming fixed calving interval of 12 mo for earlier parities. The input values for $A, y_{0}$, and $p_{2}$, were set to $650 \mathrm{~kg}, 42 \mathrm{~kg}$, and $61 \mathrm{~d}$, respectively. The input value for $p_{1}$ was $41 \mathrm{~kg}$ in first parity, $47 \mathrm{~kg}$ in second parity, and $50 \mathrm{~kg}$ in later parities. The parameter values for $k$ and $p_{3}$ were set to 0.00315 per day and 0.0187 per day, respectively.

Relative to the live weight function in van Arendonk (1985a), 3 input values were modified. First, mature weight was $650 \mathrm{~kg}$, which is a more representative value today (CVB, 2007). Second, the time within lactation when the live weight was the lowest was $61 \mathrm{~d}$, because
Van Knegsel et al. (2007) observed, using indirect calorimetry techniques, a positive energy retention in body mass in wk 8 of lactation on average. Third, $p_{1}$ was dependent on the cow's permanent production potential because high-yielding cows lose more weight in early lactation because of the greater energy need for milk production. Following Jalvingh et al. (1993), the value of $p_{1}$ was modified according to a linear relationship specifying that every $1,000 \mathrm{~kg}$ of additional milk production potential (on 305-d basis) resulted in $15 \mathrm{~kg}$ higher $p_{1}$. 